\title{
The periplasmic chaperone Skp prevents misfolding of the secretory lipase A from Pseudomonas aeruginosa
}

\author{
Athanasios Papadopoulos ${ }^{1}$, Max Busch ${ }^{1}$, Jens Reiners ${ }^{2}$, Eymen Hachani ${ }^{3}$, \\ Miriam Bäumers ${ }^{4}$, Lutz Schmitt ${ }^{3}$, Karl-Erich Jaeger ${ }^{5}$, Filip Kovacic ${ }^{5}$, \\ Sander H.J. Smits ${ }^{2,3}$ and Alexej Kedrov ${ }^{1, 凶}$
}

${ }^{1}$ Synthetic Membrane Systems, Institute of Biochemistry, Heinrich Heine University Düsseldorf, Universitätsstraße 1, 40225 Düsseldorf, Germany

${ }^{2}$ Center for Structural Studies, Heinrich Heine University Düsseldorf, Universitätsstraße 1, 40225 Düsseldorf, Germany

${ }^{3}$ Institute of Biochemistry, Heinrich Heine University Düsseldorf, Universitätsstraße 1, 40225 Düsseldorf, Germany

${ }^{4}$ Center for Advanced imaging, Heinrich Heine University Düsseldorf, Universitätsstraße 1, 40225 Düsseldorf, Germany

${ }^{5}$ Institute of Molecular Enzyme Technology, Jülich Research Center, Wilhelm-Johnen-Straße, Jülich, Germany

Corresponding author:

Dr. Alexej Kedrov

E-mail: Kedrov@hhu.de

Key words: protein secretion; protein folding; virulence factor; protein:protein interactions 


\begin{abstract}
Pseudomonas aeruginosa is a wide-spread opportunistic human pathogen and a high-risk factor for immunodeficient people and patients with cystic fibrosis. The extracellular lipase $A$ belongs to the virulence factors of $P$. aeruginosa. The lipase undergoes folding and activation in the periplasm prior the secretion. Here, we demonstrate that the ubiquitous periplasmic chaperone Skp of $P$. aeruginosa, but not SurA, FkpA, PpiD or YfgM, efficiently prevents misfolding of the aggregation-prone lipase $A$ and facilitates its activation by a specific foldase $\mathrm{LipH}$. Small-angle X-ray scattering visualizes the trimeric architecture of $P$. aeruginosa Skp and identifies two primary conformations of the chaperone, a compact and a widely open. We describe two binding modes of Skp to the lipase, with affinities of $20 \mathrm{nM}$ and $2 \mu \mathrm{M}$, which correspond to 1:1 and 1:2 stoichiometry of the lipase:Skp complex. Two Skp trimers are required to stabilize the lipase via the apolar interactions, which are not affected by high salt concentrations typical for the sputum of cystic fibrosis patients. The chaperoning effect of Skp points to its potent role in maturation and secretion of the lipase in Pseudomonas species.
\end{abstract}


bioRxiv preprint doi: https://doi.org/10.1101/2022.03.01.482502; this version posted March 1, 2022. The copyright holder for this preprint (which was not certified by peer review) is the author/funder, who has granted bioRxiv a license to display the preprint in perpetuity. It is made available under aCC-BY-ND 4.0 International license.

\section{Introduction}

The Gram-negative bacterium Pseudomonas aeruginosa is a wide-spread opportunistic human pathogen of the highest biomedical importance, as indicated by the World Health Organization ${ }^{1,2}$. The pathogenic potential of $P$. aeruginosa is associated with multiple secreted virulence factors, i.e. the extracellular enzymes, such as exotoxins, lipases and elastases, which facilitate the bacterial infection and adaptation pathways ${ }^{3}$. The lipase A (LipA; Figure $1 A$ ) belongs to the most ubiquitously secreted extracellular enzymes ${ }^{4-6}$. Secreted LipA is able to hydrolyse long- and short-chain triacylglycerols and, in cooperation with the phospholipase $C$, it facilitates the release of inflammatory mediators from the host cells ${ }^{7}$. LipA accumulates in the biofilm matrix of $P$. aeruginosa on infected tissues, where it interacts with the bacterial exopolysaccharide alginate ${ }^{8}$. Although the physiological role of this interaction is not yet clarified, the biofilm assembly contributes to the bacterial growth, differentiation, and communication within the infection cycle, so the abundant LipA is seen as an element of the bacterial pathogenicity ${ }^{8}$.

Similar to other secretory proteins, LipA is synthesised as a precursor with an $\mathrm{N}$-terminal signal peptide, a hydrophobic stretch of 26 amino acids, that targets the unfolded lipase to the general SecA:SecYEG translocation pathway ${ }^{9}$. After the translocation across the cytoplasmic membrane, the signal peptide is cleaved off to release LipA into the periplasm for folding and maturation, followed by export via the type II secretion system (T2SS) ${ }^{10}$. LipA spontaneously folds into a compact intermediate state that manifests secondary and tertiary structure, however it lacks the enzymatic activity ${ }^{11,12}$. To achieve the functional conformation prior to T2SS-mediated export, LipA of $P$. aeruginosa requires interaction with a specific foldase LipH encoded in the same operon as $\mathrm{LipA}{ }^{13,14}$. LipH is a membrane-anchored protein with its Cterminal chaperone domain protruding into the periplasm. The available crystal structure of the homologous lipase:foldase complex from Burkholderia glumae ${ }^{15}$ and extensive biochemical and bioinformatics analysis ${ }^{11,12,16,17}$ suggest that LipH-bound LipA acquires a so-called "open state", where its $\alpha$-helix 5 is displaced as a "lid" aside to provide access to the catalytic site. Thus, LipH has been described as a steric chaperone that ensures correct positioning of the LipA lid domain, being a distinct feature of the lipase maturation pathway.

In the absence of the chaperone $\mathrm{LipH}$, the non-activated LipA is prone to aggregation in the crowded bacterial periplasm, which is followed by proteolytic degradation or accumulation in inclusion bodies ${ }^{18}$. Alike, aggregation and proteolysis challenge the biogenesis of ubiquitous outer membrane proteins (OMPs), which, once translocated from the cytoplasm, should cross the periplasm prior to the integration into the outer membrane ${ }^{19,20}$. To facilitate their targeting and disaggregation, a range of ATP-independent chaperones is present in the periplasm at micromolar concentrations ${ }^{9,21}$. Widely conserved proteins SurA, Skp, and FkpA are the best- 
studied chaperones, which serve as holdases and escort client proteins to the outer membrane, while preventing their premature folding or aggregation. The soluble chaperones are further complemented by PpiD and YfgM proteins anchored at the inner membrane and associated with the SecYEG translocon ${ }^{22,23}$. Notably, the periplasmic chaperones are also involved in biogenesis of several secretory proteins, including a bacterial lipase ${ }^{24-27}$, but the mechanism of these interactions has been barely investigated.

Here, we demonstrate that folding of LipA is challenged by the high aggregation propensity of its lid domain, while a mutation within this region as well as interactions with the foldase LipH greatly stabilize the protein. When examining interactions of LipA with the general periplasmic chaperones of $P$. aeruginosa, we discover a potent anti-aggregation effect of the chaperone Skp, while LipA:Skp interactions do not prevent LipH-mediated activation of the lipase. The structural analysis of Skp reveals a characteristic jellyfish-shaped trimeric assembly and suggests extensive conformational dynamics. The hydrophobic central cavity within the Skp trimer may expand largely to accommodate a LipA molecule, although two bound copies of Skp trimer are required to prevent LipA from aggregation. The results suggest that Skp may be a potent chaperone in the LipA biogenesis pathway that ensures client's maturation under challenging environmental conditions. 


\section{Results}

LipA aggregation is mediated by the lid domain

To investigate folding and activation of the lipase in vitro, LipA lacking the $\mathrm{N}$-terminal signal peptide was heterologously overexpressed in E. coli. The overexpression resulted in formation of inclusion bodies consisting nearly exclusively of LipA, and the protein was isolated in the urea-denatured state (Figure 1B). The denatured LipA is a relevant mimetic of the protein that enters the periplasm as an unfolded polypeptide chain, and it was used for the further analysis. To examine whether the recombinant protein may be refolded into its functional form, LipA was diluted into the urea-free low-salt TGCG buffer ( $5 \mathrm{mM}$ Tris pH 9.0, $5 \mathrm{mM}$ glycine, $1 \mathrm{mM} \mathrm{CaCl} 2$ and $5 \%$ glycerol) ${ }^{6}$ and incubated in the presence of the foldase chaperone LipH. The enzymatic activity of LipA was assessed then via measuring the hydrolysis of a model substrate, para-nitrophenyl-butyrate ( $p N P B$ ): Accumulation of the product, $p$-nitrophenolate, was followed colorimetrically until reaching the signal saturation, and the activity of the lipase A was quantified (Figures $1 \mathrm{C}$ and $\mathrm{D}$ ). In the absence of $\mathrm{LipH}$, the signal remained at the level of the autohydrolysis of $p$ NPB, so the hydrolytic activity of LipA was not induced. Thus, the recombinant LipA could be folded in vitro, and LipH was required for activation of LipA.

Notably, if LipA was incubated in the urea-free buffer prior to adding the foldase LipH, its hydrolytic activity was substantially reduced, as the amount of $p$-nitrophenolate generated in the first 15 min of the reaction decreased three-fold (Figure $1 \mathrm{C}$ and D). We speculated that the lipase underwent aggregation/misfolding in the absence of the foldase $\mathrm{LipH}$, causing the loss of activity. Indeed, approx. $50 \%$ of LipA could be sedimented upon mild centrifugation at 21000 $g$ (Figure 2A). The sedimentation was enhanced upon increasing the ionic strength of the solution, reaching $70 \%$ and $95 \%$ in the presence of 50 and $150 \mathrm{mM} \mathrm{NaCl}$, respectively (Figure 2B) and abundant large particles were observed by negative-stain electron microscopy (Suppl. Figure $1 \mathrm{~A}$ ). The stoichiometric amount of LipH stabilised the lipase, although the efficiency decreased at the elevated salt concentrations (Figure 2B). Since LipA:LipH binding is primarily driven by electrostatic interactions ${ }^{11,12,15}$, the affinity of the complex was likely reduced at the elevated ionic strength and LipA aggregation became a dominant pathway even in the presence of the chaperone.

Based on its amino acid sequence, the $\alpha$-helix 5 known as the "lid domain" of LipA is predicted to be the primary aggregation-prone region within the protein, with a high propensity to misfold into $\beta$-strands (Figure $2 \mathrm{C}$, red line) ${ }^{28}$. Previous studies on a homologous lipase demonstrated that a point mutation Phe to Glu within the lid domain diminished the aggregation propensity and rendered an aggregation-resistant protein ${ }^{29}$. Based on the structure homology, we recognised an identically positioned phenylalanine residue within $P$. aeruginosa PAO1 LipA at position 144 , where the point mutation to glutamate could suppress the lipase misfolding 
(Figure 2C, black line). To examine the effect of the mutation on the lipase folding and activity, the mutant LipA $\mathrm{F}_{\mathrm{F} 14 \mathrm{E}}$ was overexpressed and isolated in its urea-denatured state. In the presence of $\mathrm{LipH}$, LipA $\mathrm{F}_{\mathrm{F} 14 \mathrm{E}}$ displayed the enzymatic activity, indicating that the mutation did not hinder the chaperone-mediated folding (Figure $1 \mathrm{C}$ and $\mathrm{D}$ ). Indeed, the lid domain is not involved in LipA:LipH contacts ${ }^{15}$, and the mutated residue is oriented toward the solvent and does not belong to the moiety of the catalytic site (Figure $1 \mathrm{~A}$ ).

To examine whether LipA $\mathrm{F}_{\mathrm{F} 144 \mathrm{E}}$ is indeed more resistant against aggregation than the wild-type lipase, its solubility was probed over a range of salt concentrations. The point mutation had a notable effect on the protein stability: Nearly $50 \%$ of $L_{i p A_{F 144 E}}$ remained soluble in the presence of $100 \mathrm{mM} \mathrm{NaCl}$, where the soluble fraction of the wild-type LipA did not exceed 15 $\%$ (Figure $2 \mathrm{~B}$ ). As the aggregated lipase tends to form amyloid-type structures ${ }^{29}$, we further

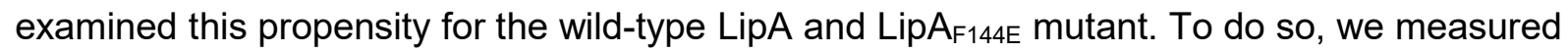
the fluorescence intensity of the dye thioflavin T (ThT), which fluorescence increases manifold upon binding to $\beta$-strands within amyloid-type aggregates ${ }^{30}$. Once the dye was added to the wild-type lipase in the TGCG buffer supplemented with $20 \mathrm{mM} \mathrm{NaCl}$, its fluorescence intensity increased 10-fold, suggesting that $\beta$-stranded structures were formed even at the low salt concentration (Figure 2D and Suppl. Figure 2B). In contrast, the ThT fluorescence was only modestly affected in the presence of LipA $\mathrm{F}_{144 \mathrm{E}}$, increasing 3-fold above the signal of free ThT, in agreement with the reduced aggregation of the mutant.

As both the mutation within the lid domain of LipA and the LipA:LipH assembly favoured the soluble state of the lipase, we questioned whether both cases involve the same stabilisation mechanism. To address this, the solubility of the wild-type LipA and LipA $A_{F 144 E}$ in the presence of the foldase was compared (Figure $2 B$ ). Strikingly, the solubility of the mutant LipA $A_{F 144 E}$ was further enhanced by $\mathrm{LipH}$ : At elevated salt concentrations, the fraction of the soluble LipA $\mathrm{A}_{\mathrm{F} 144 \mathrm{E}}$ exceeded approx. two-fold that of the wild-type LipA, so even at $250 \mathrm{mM} \mathrm{NaCl}$ the major fraction of LipA $A_{F 144 E}: L i p H$ remained soluble. Conclusively, the effects of the mutation within the lid domain and the lipase:foldase binding were additive, and distinct mechanisms contributed to the lipase stabilisation.

\section{Characterisation of periplasmic chaperones of $P$. aeruginosa}

The extensive aggregation of the wild-type LipA observed already at moderate salt concentrations is a potential challenge for its timely interactions with the stabilising foldase $\mathrm{LipH}$, especially under high-salinity conditions within cystic fibrosis patients' sputum ${ }^{31}$. As the highly abundant periplasmic chaperones may facilitate folding and secretion of several recombinant proteins, including a lipase of Burkholderia ${ }^{24-27,32}$, we speculated that the 
chaperones of $P$. aeruginosa may recognize LipA and protect it from aggregation prior interactions with the specific foldase $\mathrm{LipH}$.

To characterize LipA:chaperone interactions in a well-defined in vitro system, the primary soluble chaperones Skp, FkpA and SurA lacking their signal peptides (Figure 3A), as well as the periplasmic domains of $\mathrm{YfgM}$ and PpiD of $P$. aeruginosa PAO1 were heterologously expressed and purified from E. coli. The apparent molecular weights of the chaperones observed in SDS-PAGE agreed with the values calculated for individual protomers (18 kDa for Skp, 20 kDa for YfgM, 27 kDa for FkpA, 47 kDa for SurA and 67 kDa for PpiD; Figure 3B). To scrutinise the oligomeric states of the isolated chaperones, their native masses were determined by size exclusion chromatography combined with multi-angle light scattering analysis (SEC-MALS, Figure 3C). The experiment revealed monomers of SurA (determined molecular weight of $49.6 \pm 0.6 \mathrm{kDa})$, dimers of FkpA $\left(53.2 \pm 0.9 \mathrm{kDa} ; \mathrm{FkpA}_{2}\right)$, and trimers of Skp $\left(58.6 \pm 0.7 \mathrm{kDa} ; \mathrm{Skp}_{3}\right)$, in agreement with the known structures of homologs from $E$. coli ${ }^{33-35}$. The periplasmic domains of both YfgM and PpiD were found to be monomers, with molecular masses of $22.2 \pm 0.4 \mathrm{kDa}$ and $72.2 \pm 0.2 \mathrm{kDa}$, respectively. The periplasmic chaperone domain of $\mathrm{LipH}$ appears to be monomeric in solution (determined molecular weight $39.4 \pm 0.3 \mathrm{kDa}$ ). The attempts to analyse the molecular mass of either wild-type LipA or LipA $A_{F 144 E}$ were not successful, as the hydrophobic protein was possibly interacting with the column matrix and could not be eluted with aqueous buffers.

\section{The chaperone Skp prevents LipA from aggregation}

The propensity of the individual chaperones to prevent LipA aggregation was first evaluated by the sedimentation analysis. To mimic the natural abundance of SurA, $\mathrm{FkpA}_{2}$ and $\mathrm{Skp}_{3}$ in the bacterial periplasm, $5 \mu \mathrm{M}$ of chaperones were used in the experiments ${ }^{9,21}$, corresponding to the lipase:chaperone molar ratio $1: 10$, and the salt concentration was set to $150 \mathrm{mM} \mathrm{NaCl}$. In the absence of the chaperones, only $10 \%$ of LipA was found in the soluble form, and the value increased moderately in the presence of either SurA or $\mathrm{FkpA}_{2}$ (solubility of $15 \%$ and 29 $\%$, respectively; Figure $4 \mathrm{~A}$ and $\mathrm{B}$ ). In contrast, $\mathrm{Skp}_{3}$ demonstrated prominent stabilisation of LipA, as the soluble fraction reached $66 \%$. In the presence of the lipase-specific foldase $\mathrm{LipH}$, more than $80 \%$ LipA was found soluble (LipA:LipH molar ratio 1:1).

The membrane-anchored proteins PpiD and YfgM are the recently described chaperones associated with the SecYEG translocon of $E$. coli ${ }^{23,36}$. Being proximal to the translocon, the peptidyl prolyl isomerase PpiD and the tetratricopeptide repeat-containing protein $\mathrm{YfgM}$ of $P$. aeruginosa may interact with LipA at the early stage of its translocation into the periplasm and mediate the handover to the membrane-anchored $\mathrm{LipH}$. Similar to the soluble chaperones above, the potential effects of the periplasmic domains of PpiD and YfgM on LipA aggregation 
were investigated. YfgM did not stabilize LipA, as the soluble fraction remained below $20 \%$ (Figure 4A and B). This lack of the holdase activity is in agreement with earlier experiments, where luciferase and the precursor of OmpC were tested as putative YfgM clients ${ }^{23}$. In the presence of PpiD, the soluble fraction of LipA increased up to $34 \%$, which matched closely the value measured for another peptidyl prolyl isomerase, FkpA. Overall, the sedimentation assay identified the non-specific soluble chaperone Skp as a potent stabilising factor of the lipase.

Next, we questioned whether the chaperones may be capable of preventing the assembly of amyloid-type aggregates of LipA. To probe this putative effect, ThT fluorescence was measured for LipA in the presence of individual chaperones and corrected to the values of the chaperones alone (Suppl. Figure 2). Although most of the chaperones had moderate to low effect on LipA solubility in the sedimentation assay (Figure 4B), they all could reduce the ThT fluorescence at least by $40 \%$, as compared to LipA alone or LipA in the presence of bovine serum albumin (BSA) (Figure 4C). These values reflect the partial ability of chaperones to prevent amyloid-like structure formation by LipA. Notably, the most prominent effect was observed again for Skp, as the amyloid-specific ThT signal in the presence of the chaperone was reduced by approx. $75 \%$. Similar low ThT fluorescence intensity was recorded in the presence of $\mathrm{LipH}$.

Finally, negative-stain electron microscopy was used to visualize LipA aggregation. At the elevated ionic strength and in the absence of urea, LipA readily formed micrometer-sized aggregates, commonly assembled in larger clusters (Suppl. Figure 1A and Figure 4D). The sample morphology was altered when either $\mathrm{LipH}$ or $\mathrm{Skp}_{3}$ were added at the molar ratios of $1: 1$ and 1:10, respectively, so only sub-micrometer featureless particles could be observed, suggesting reduced aggregation propensity. Thus, we concluded that both Skp and LipH offer protection from the assembly of aggregates, despite different mechanisms of interaction with the lipase.

\section{The periplasmic chaperones modulate the activation of LipA}

The interactions of the periplasmic chaperones with LipA and their anti-aggregation effects may affect the functionality of the lipase, e.g. by directly altering its folding pathways and/or by competing with the specific foldase LipH. None of the general periplasmic chaperones alone rendered the active lipase, as no enzymatic hydrolysis of $p$ NPB was observed in the absence of $\mathrm{LipH}$ (Figure 5A). To examine the potential competition between the chaperones, we focused on the LipH-mediated activation of LipA in the presence of the general periplasmic chaperones, as it occurs in living cells. The wild-type LipA was pre-incubated in the presence or absence of individual chaperones under conditions of moderate ionic strength $(50 \mathrm{mM} \mathrm{NaCl}$, 
bioRxiv preprint doi: https//doi.org/10.1101/2022.03.01.482502; this version posted March 1, 2022. The copyright holder for this preprint (which was not certified by peer review) is the author/funder, who has granted bioRxiv a license to display the preprint in perpetuity. It is made available under aCC-BY-ND 4.0 International license.

$1 \mathrm{mM} \mathrm{CaCl}_{2}$ and $20 \mathrm{mM}$ Tris- $\mathrm{HCl} \mathrm{pH} \mathrm{8.0)} \mathrm{sufficient} \mathrm{to} \mathrm{induce} \mathrm{the} \mathrm{lipase} \mathrm{aggregation.} \mathrm{After} \mathrm{the}$ pre-incubation phase, the foldase LipH was added to activate LipA, and the resulting hydrolytic activity against $p$ NPB was determined (Figure 5B). The conditions of the pre-incubation phase had clear influence on the enzymatic activity of LipA: In the sample to which no chaperones were initially added, LipA activity was suppressed to a large extent (blue bars in Figures 5A vs $5 \mathrm{~B})$, in agreement with the documented aggregation of the lipase. Notably, the pre-incubation in the presence of SurA, FkpA, YfgM or PpiD chaperones led to further two- to four-fold decrease in LipA activity (Figure 5B). Differently though, pre-incubation of LipA with $\mathrm{Skp}_{3}$ resulted in modest stimulation of the substrate hydrolysis, in agreement with the antiaggregation effect of the chaperone.

The reduced LipA activity in the presence of FkpA, SurA, YfgM or PpiD correlated with their poor propensity to prevent LipA aggregation, but also suggested the interference with the LipHmediated activation, potentially by competing for the lipase binding. To examine this scenario, both, the general chaperones and LipH, were added to LipA simultaneously at the LipA:LipH:chaperone molar ratio of $1: 1: 10$, so the lipase activity was dependent on the folding/aggregation balance and the competition between the chaperones for the lipase. In the presence of either SurA, FkpA, YfgM or PpiD, the activity of LipA dropped by 30-50\% (Figure $5 \mathrm{C}$ ), while only minor, below $10 \%$ inhibition of substrate hydrolysis was observed for $\mathrm{LipA}: \mathrm{LipH}: \mathrm{Skp}_{3}$ sample. Finally, to scrutinise the effect of the chaperone competition, the assay was conducted using the aggregation-resistant LipA $A_{F 144 E}$ mutant (Figure 5D). When either SurA, $\mathrm{FkpA}_{2}, \mathrm{YfgM}$ or PpiD were present in addition to LipH, the lipase activity reduced by 20 to $30 \%$, so we concluded that the chaperones interfered with the LipH:LipA assembly. The effect of $\mathrm{Skp}_{3}$ on LipH-mediated activation was minimal, so the chaperone allowed efficient LipH:LipA interactions, while being capable of preventing LipA aggregation.

\section{Trimeric Skp of $P$. aeruginosa acquires multiple conformations in solution}

As the biochemical experiments highlighted a potent role of Skp in LipA folding, we set out to shed more light on the functional mechanism of the chaperone. The well-studied Skp homolog from E. coli (EcSkp) forms a "jellyfish"-like trimer that resembles the arrangement of prefoldintype chaperones of mitochondria and archaea ${ }^{34,37}$. Each protomer consists of the distinct "head" and "arm" domains. The "head" domain of EcSkp is predominantly formed by $\beta$-sheets which drive the oligomerization, and the "arm" domain is a helical section forming a hairpin extension. The client-binding pocket between the "arm" domains is constituted by all three promoters. The crystal structures and small-angle X-ray scattering (SAXS) experiments predicted a broad range of conformations for the EcSkp trimer in its apo-state in solution, where three major states termed as "closed", "intermediate" and "open" were described ${ }^{38}$. 
bioRxiv preprint doi: https//doi.org/10.1101/2022.03.01.482502; this version posted March 1, 2022. The copyright holder for this preprint (which was not certified by peer review) is the author/funder, who has granted bioRxiv a license to display the preprint in perpetuity. It is made available under aCC-BY-ND 4.0 International license.

Mature Skp of $P$. aeruginosa shares $22 \%$ sequence identity with EcSkp and contains three unique proline residues per protomer, including two prolines in the predicted "head" domain and one in each helical "arm", which may alter the flexibility of the chaperone (Suppl. Figure 3). Thus, we employed SAXS to experimentally assess the conformational ensemble of $P$. aeruginosa Skp in solution (Figure 6A and Suppl. Table 1). In agreement with SEC-MALS data (Figure 3), Skp was found to be a trimer $\left(\mathrm{Skp}_{3}\right)$. The characteristic "jellyfish"-like shape with the "head" and "arm" domains of the trimer could be recognized in the ab initio reconstitution of the oligomer structure using the GASBOR program ${ }^{39}\left(X^{2}=1.016\right)$ (Figure $6 A$ and $\left.B\right)$. A structural model of $\mathrm{P}$. aeruginosa $\mathrm{Skp}_{3}$ built by AlphaFold 2 algorithm ${ }^{40,41}$ could be fitted into the experimental SAXS envelope (Figure 6B). However, the measured radius of gyration $\left(R_{\mathrm{g}}\right)$ of $3.50 \mathrm{~nm}$ for the averaged SAXS data is slightly higher than $R_{g}$ of $3.32 \mathrm{~nm}$ calculated via CRYSOL for the modelled structure $\left(X^{2}=1.28\right)^{42}$, so $\mathrm{Skp}_{3}$ of $P$. aeruginosa adopts a more open conformation.

The SAXS data also revealed some flexibility in $\mathrm{Skp}_{3}$ of $P$. aeruginosa, like previously observed for the EcSkp homolog ${ }^{38}$. To characterize this conformational space, Ensemble Optimization Method (EOM) was applied ${ }^{43,44}$. EOM generates a pool of sequence- and structure-based models (Figure 6C, RANCH models), and the implemented genetic algorithm GAJOE (Genetic Algorithm Judging Optimisation of Ensembles) selects an ensemble until an optimal fit to the experimental SAXS curve is reached. The selected models describe best the experimental SAXS data, and likely represent the most frequent conformations of the studied protein (Figure $6 \mathrm{~B})$. To model the $\mathrm{Skp}_{3}$ dynamics by EOM, the "head" domain within the trimer was fixed and the helical "arms" were allowed moving to fit the SAXS data. As a result, the selected ensemble matched the experimental SAXS curves with $X^{2}=0.954$ (Figure 6A, EOM models). The distribution of the models showed two primary states, resembling those reported for $\operatorname{EcSkp}_{3}{ }^{38}$ : The "compact" state with $R_{\mathrm{g}}$ of $3.42 \mathrm{~nm}$ and maximal dimensions $\left(D_{\max }\right)$ of $9.73 \mathrm{~nm}$, which accounts up to $62 \%$ of the population, and the "open" state $\left(R_{\mathrm{g}}=4.14 \mathrm{~nm}, D_{\max }=13.63 \mathrm{~nm}\right.$; $12 \%$ occupancy) (Figure $6 \mathrm{D}$ ). While the dimensions of the open state were nearly identical for both $\mathrm{Skp}_{3}$ homologs, the compact state of $\mathrm{Skp}_{3}$ of $P$. aeruginosa was wider than the "intermediate" conformation of $\operatorname{EcSkp}_{3}\left(R_{\mathrm{g}}\right.$ of $3.42 \mathrm{~nm}$ vs. $3.2 \mathrm{~nm}$ ), and no "closed" state was observed for $\mathrm{Skp}_{3}$ of $P$. aeruginosa. Nevertheless, the ability of $\mathrm{Skp}_{3}$ of both $E$. coli and $P$. aeruginosa to undergo a large conformational change from a compact to a widely open state suggests that the proteins likely follow the same functional mechanism.

Two copies of Skp are required to stabilize soluble LipA via apolar contacts

The documented clients of Skp in the bacterial periplasm span a broad range of molecular masses, from 19 to $89 \mathrm{kDa}$, and they belong to various classes, both membrane-associated and globular proteins ${ }^{45,46}$. Notably, the stimulatory effect of Skp on secretion of a bacterial 
bioRxiv preprint doi: https//doi.org/10.1101/2022.03.01.482502; this version posted March 1, 2022. The copyright holder for this preprint (which was not certified by peer review) is the author/funder, who has granted bioRxiv a license to display the preprint in perpetuity. It is made available under aCC-BY-ND 4.0 International license.

lipase has been previously demonstrated, but it remained obscure whether the stimulation was indeed a result of direct client:chaperone interactions ${ }^{27}$. Our biochemical data substantiates the view that $\mathrm{Skp}_{3}$ is a potent chaperone that prevents the lipase aggregation, and here we set out to characterize LipA:Skp 3 interactions in detail.

Firstly, we questioned whether the interaction of $P$. aeruginosa $\mathrm{Skp}_{3}$ with LipA is indeed of hydrophobic nature, as each of the "arms" within the Skp trimer has an apolar side (Figure 7A) that may bind unfolded and/or misfolded clients. As shown for the LipA:LipH complex, elevated ionic strength of the aqueous solution severely destabilizes the hydrophilic binding interface, so the released LipA irreversibly aggregates (Figure 2B). Hydrophobic interactions, in contrast, should be insensitive to the ionic strength and may facilitate the chaperoning at high salt concentrations. The solubility of LipA in the presence of $\mathrm{Skp}_{3}$ at the molar ratio 1:10 was examined over a range of $\mathrm{NaCl}$ concentrations via the sedimentation assay (Figure 7B). Different to LipA alone and LipA in the presence of $\mathrm{LipH}$, no decay in the soluble fraction was observed when $\mathrm{Skp}_{3}$ was present. At the highest examined concentration of $250 \mathrm{mM} \mathrm{NaCl}$, $\mathrm{Skp}_{3}$ ensured the lipase solubility of approx. $70 \%$, while the chaperone-free LipA was nearly completely aggregated, and only $30 \%$ of LipA was found soluble in the presence of LipH. This observation implied that the lipase is recognized via non-polar contacts, likely associated with the unfolded state.

Next, we set out to determine the binding affinity of Skp to LipA. Earlier studies of Skp interactions with its most abundant clients, OMPs, provided the affinity estimates at lownanomolar to low-micromolar scales for OMP:Skp $\mathrm{S}_{3}$ complexes formed at $1: 1$ and $1: 2$ stoichiometry, respectively ${ }^{45-48}$, while the interactions with soluble proteins have not been addressed. For the analysis here, we employed microscale thermophoresis (MST) and used the aggregation-resistant mutant $\mathrm{LipA}_{\mathrm{F} 144 \mathrm{E}}$ as the fluorescently labelled component. Lip $\mathrm{A}_{\mathrm{F} 144 \mathrm{E}}-$ FM was mixed with Skp ranging from $4.5 \mathrm{nM}$ to $37 \mu \mathrm{M}$ (concentration of Skp monomers), and the MST response of $\mathrm{LipA}_{\mathrm{F} 144 \mathrm{E}}-\mathrm{FM}$, i.e. its mobility within the micrometer-sized temperature gradient, was analysed. Strikingly, LipA ${ }_{F 144 E}$ manifested a bimodal MST response upon increasing the Skp concentration that appeared as a V-shaped plot with a transition at approx. $300 \mathrm{nM} \mathrm{Skp}_{1}\left(100 \mathrm{nM} \mathrm{Skp}_{3}\right.$ ) (Figure 7C). The data suggested two distinct modes of binding to the chaperone, where individual $\mathrm{K}_{\mathrm{D}}$ 's were $\sim 20 \mathrm{nM}$ and $2 \mu \mathrm{M}$, and the values were in a good agreement with values measured for $\mathrm{OMP}: \mathrm{Skp}_{3}$ interactions where either one or two $\mathrm{Skp}$ timers were involved ${ }^{45-47}$.

The LipA:Skp affinity measured in the MST experiments suggested that two copies of Skp trimer were recruited to stabilize the soluble lipase (Figures 4 and 5; monomeric Skp of 15 $\mu \mathrm{M})$. To test the stoichiometry of the complex experimentally, SEC-MALS analysis was performed on LipA $_{F 144 \mathrm{E}}$ :Skp mixture (molar ratio 1:3; Figure 7D). The elution peak 
demonstrated a prominent shift in comparison to $\mathrm{Skp}_{3}$ alone, and the estimated molecular mass of $139 \mathrm{kDa}$ approached closely the calculated mass of the complex LipA:2* ${ }^{*} \mathrm{kp}_{3}$ (148 $\mathrm{kDa}$ ). SDS-PAGE confirmed presence of both the chaperone and the lipase in the peak fractions, and the densitometry analysis of the corresponding bands suggested the excess of Skp (estimated LipA:Skp 3 ratio 1:3). The remaining free LipA fraction was likely bound to the column resin, as we observed previously. Thus, we concluded that the relatively small protein LipA provided sufficient surface area for binding two copies of the trimeric Skp. To test, whether this stoichiometry was beneficial for the solubility of the lipase, we used the aggregation-prone wild-type LipA in the sedimentation assay where the LipA:Skp 3 ratio was varied. Strikingly, the solubility of LipA dropped dramatically when LipA:Skp $p_{3}$ molar ratio was reduced to $1: 1$ (monomeric Skp $1.5 \mu \mathrm{M}$ ), suggesting that a single Skp trimer was not capable of rescuing the client from aggregation/misfolding. It seems plausible that at elevated Skp concentrations, two copies of the chaperone lock LipA within the consolidated cavity, and rapid re-binding of the escaped clients occurs prior to the irreversible aggregation. 


\section{Discussion}

The protein fold is determined by its primary amino acid sequence, but the pathways followed by the polypeptide chain towards the functional structure commonly involve the assistance of chemical and proteinaceous chaperones. The chaperones steer their client dynamics along the energy landscape, facilitate the local and global folding/unfolding events, prevent offpathway intermediates, and serve to disaggregate occasional misfolded structures ${ }^{49,50}$. The role of chaperones is of particular importance under stress factors, such as elevated temperature, or in challenging environments, such as bacterial periplasm, where the protein folding should proceed under broadly varying conditions. Here, we demonstrate that the nonspecific periplasmic chaperone Skp of the pathogenic bacterium $P$. aeruginosa efficiently protects the secretory lipase LipA from aggregation and suppresses its assembly into amyloidtype structures. The structural analysis of trimeric Skp in solution by SAXS reveals an ensemble of co-existing states. The interaction analysis of the LipA:Skp ${ }_{3}$ complex suggests that either one and two copies of Skp trimers may bind the lipase via hydrophobic interactions, but two copies are required for stabilizing the aggregation-prone protein.

Folding of the lipase LipA takes place in the periplasm, where the protein is transiently localized and interacts with the specialized chaperone $\mathrm{LipH}$. The chaperone serves for correct positioning of the lid domain of LipA, thus rendering the active enzyme prior its further secretion via T2SS ${ }^{14,15}$. The non-activated lipase tends to acquire loosely folded intermediate states, which are accessible for proteases and prone to aggregation ${ }^{18,51}$. The chaperone-dependent folding is not common among bacterial lipases, and it might be related to the particular structure of the lid domain ${ }^{52}$. In agreement with the earlier findings of Chiti and co-workers 29,51, our data show that the lid domain greatly contributes to LipA aggregation and misfolding into $\beta$-stranded structures, thus interfering with the protein biogenesis. As the assembly of the LipA:LipH complex rescues LipA from aggregation to a large extent, two distinct functions can be assigned to $\mathrm{LipH}$, namely stabilization and activation of the client lipase. Speculatively, the chaperone might initially serve to stabilize the lipase in its folded state and hand it over to T2SS, and through the course of the evolution it has gained the propensity to activate the lipase via steric re-positioning of the lid domain.

Several challenges can be envisioned for productive LipA:LipH interactions in the living cell. Firstly, the expression levels of the foldase are substantially lower than those of LipA, so each LipH molecule should carry out multiple chaperoning cycles upon binding nascent lipases, refining the structure and releasing them for further secretion ${ }^{14}$. Secondly, the accessibility of the membrane-anchored foldase for its client may be limited, especially in the crowded periplasmic environment. Finally, the elevated ionic strength encountered in the sputum of cystic fibrosis patients ${ }^{31,53}$ strongly promotes the aggregation of LipA and may also inhibit the electrostatic interactions at the LipA:LipH interface. Thus, accessory factors, such as non- 
bioRxiv preprint doi: https//doi.org/10.1101/2022.03.01.482502; this version posted March 1, 2022. The copyright holder for this preprint (which was not certified by peer review) is the author/funder, who has granted bioRxiv a license to display the preprint in perpetuity. It is made available under aCC-BY-ND 4.0 International license.

specific but ubiquitous periplasmic chaperones may be beneficial for biogenesis of the intrinsically unstable lipase. Here, we elucidate that $\mathrm{Skp}_{3}$, a conditionally essential protein in $P$. aeruginosa ${ }^{54}$, is a potent holdase for LipA that efficiently maintains the soluble state of the lipase and blocks the assembly of $\beta$-structured aggregates. Notably, even 10 -fold excess of $\mathrm{Skp}_{3}$ did not inhibit LipA activation and thus allowed LipA:LipH interactions, so we described the chaperone as a putative factor in LipA biogenesis that steers folding pathways by preventing aggregation events.

Up to date, the vast majority of insights on Skp functioning have been gained from studies on the chaperone from E. coli. Differently from other periplasmic chaperones, Skp targets its clients based on the hydrophobicity exposed in the unfolded/misfolded structures rather than a specific sequence motif or conformations of proline residues ${ }^{46,55}$. The periplasmic concentration of EcSkp may reach hundreds of $\mu \mathrm{M}^{9}$, and the chaperone extensively interacts with unfolded OMPs ${ }^{46,47,56}$. Although no OMP essentially depends on Skp in the presence of SurA ${ }^{56,57}$, other moonlighting activities have been suggested exclusively for Skp. Recently, the chaperone has been described as an adaptor protein that delivers the misfolded OMP LamB to the periplasmic protease DegP ${ }^{58}$. Skp is a potent disaggregase of another OMP, OmpC ${ }^{59}$ and it also demonstrates the holdase and disaggregase activity towards several soluble proteins $25,26,60$. Most notably, heterologous expression and secretion of a lipase from Burkholderia could be substantially improved in E. coli upon co-expression of Skp, but not SurA ${ }^{27}$, and the Skp-mediated solubility of the lipase was proposed as the decisive factor, in agreement with our direct biochemical evidences. While the functional insights on Skp of $P$. aeruginosa are sparse ${ }^{61}$, the chaperone appears to be essential for the survival of bacteria in the sputum media, where the salt concentration exceeds $100 \mathrm{mM}^{54}$.

Structural analysis on $\mathrm{Skp}_{3}$ of $P$. aeruginosa suggests that its architecture and dynamics resemble those of $\mathrm{ECSkp}_{3}$, despite the low sequence similarity and presence of multiple proline residues. $P$. aeruginosa Skp exists as an assembled trimer in solution, and its conformational plasticity and the hydrophobic interior fulfil the requirements for being a promiscuous nonspecific holdase chaperone. The SAXS data describe the transient outward motion of the "arm" domains that ensures opening of the interior cavity of the Skp trimer. The aggregation-prone folding intermediates of LipA are likely to be recognized by $\mathrm{Skp}_{3}$, kept in the protective hydrophobic cavity and then handed over to LipH for activation.

Using the aggregation-resistant lipase mutant LipA $\mathrm{F}_{\mathrm{F} 144 \mathrm{E}}$ allowed estimating its affinity to Skp. MST measurements revealed a complex biphasic binding with affinities of $\sim 20 \mathrm{nM}$ and $2 \mu \mathrm{M}$. These affinities are in a remarkable agreement with the values measured for Skp interaction with various OMPs, where binding of either one or two copies of $\mathrm{Skp}_{3}$ has been described ${ }^{45-}$ 48. The close match between the Skp affinities to different classes of clients is likely due to non- 
specific hydrophobicity-based interactions. Unexpectedly though, the relatively small protein LipA is able to recruit two trimers of Skp, suggesting that the exposed hydrophobic areas are sufficiently large to form the extensive binding interface.

Our data provide first evidence for selective interactions of $P$. aeruginosa LipA with the general and highly abundant periplasmic chaperone Skp that result in stabilization of the lipase. It remains to be shown to what extent Skp is involved in LipA biogenesis in $P$. aeruginosa, and whether the chaperone:client interactions are beneficial at particular conditions, such as elevated ionic strengths. Future experiments in the native environment of $P$. aeruginosa combined with in vitro analysis will account for the membrane-anchored $\mathrm{LipH}$ and its putative competition with Skp for the nascent LipA, as well as the handover of LipA to the T2SS machinery and potential involvement of Skp at that stage. 


\section{Materials and methods}

\section{Molecular cloning}

The genes of $P$. aeruginosa PAO1 strain were identified using Pseudomonas Genome Database (www.pseudomonas.com). Those included PA2862 (lipA), PA2863 (lipH), PA3262 (fkpA), PA3801 (yfgM), PA1805 (ppiD), PA0594 (surA) and PA3647 (skp/ompH/hlpA). The genomic DNA from $P$. aeruginosa $\mathrm{PAO} 1$ served as a template for the amplification of the genes of interest via PCR using the KOD Xtreme polymerase (Novagen/Merck) and cloning primers containing the restriction sites (Eurofins Genomics). The PCR products were isolated using the NucleoSpin Gel and PCR Clean-up kit (Macherey-Nagel). Standard molecular cloning techniques were further employed to insert the genes of interest into target vectors using restriction nucleases (New England Biolabs). The amplified genes encoding the full-length periplasmic chaperones were initially cloned into the pET21a vector to contain C-terminal hexa-histidine tags. The following combinations of the restriction sites were used for cloning: BamHI/HindIII for skp and surA, EcoRI/HindIII for yfgM and ppiD, and EcoRI/Sall for fkpA. The positions of signal peptides and membrane-anchoring domains within the chaperones were identified using SignalP-5.0 and TMHMM services, respectively ${ }^{62,63}$. For overexpression of the soluble proteins, the regions encoding the $\mathrm{N}$-terminal signal peptides and the membrane anchors were removed via PCR and the plasmids were re-ligated. E. coli strain DH5a (Thermo Fisher Scientific) served as a recipient strain for cloning and plasmid multiplication. Plasmid DNA was isolated using the NucleoSpin Plasmid kit (Macherey-Nagel) and analysed by Sanger sequencing (Eurofins Genomics).

\section{Expression and purification of periplasmic chaperones}

The soluble chaperones were heterologously expressed in E. coli BL21(DE3), and Skp was expressed in E. coli BL21(DE3)pLysS. Overnight cultures were grown at $37^{\circ} \mathrm{C}$ upon shaking at $180 \mathrm{rpm}$ and used for inoculation of pre-warmed LB medium. Cells were grown at $37^{\circ} \mathrm{C}$ upon shaking at $180 \mathrm{rpm}$ until reaching $\mathrm{OD}_{600} 0.6$, and overexpression was induced with 0.5 $\mathrm{mM}$ isopropyl-ß-D-thiogalactopyranoside (IPTG; Merck/Sigma-Aldrich). After 2 hours expression the cells were harvested by centrifugation at $6000 \mathrm{~g}$ for $15 \mathrm{~min}, 4^{\circ} \mathrm{C}$ (rotor SLC6000 , Sorvall/Thermo Fischer) and resuspended in $50 \mathrm{mM} \mathrm{KCl}, 1 \mathrm{mM} \mathrm{DTT}, 10 \%$ glycerol, 20 mM HEPES pH 7.4 supplemented with protease inhibitors (cOmplete Protease Inhibitor Cocktail, Roche). The cells were lysed by shear force (M-110P cell disruptor, Microfluidics Inc.) and the debris and membranes were removed by ultracentrifugation at 205,000 $\mathrm{g}$ for $1 \mathrm{hr}$ at 4 ${ }^{\circ} \mathrm{C}$ (rotor $45 \mathrm{Ti}$, Beckman Coulter). The supernatants were applied to IMAC with $\mathrm{Ni}^{2+}-\mathrm{NTA}$ agarose resin (Qiagen) in the presence of $5 \mathrm{mM}$ imidazole. After binding and extensive wash with the resuspension buffer containing $10 \mathrm{mM}$ imidazole to remove weakly and nonspecifically bound proteins, the chaperones were eluted with the buffer supplemented with 300 
$\mathrm{mM}$ imidazole. The elution fractions were concentrated and subjected to SEC using Superdex 200 Increase 10/300 GL column (Cytiva). Fractions containing the chaperones were identified by SDS-PAGE, and the protein concentrations were determined spectrophotometrically based on calculated extinction coefficients at $280 \mathrm{~nm}$ : SurA $30940 \mathrm{M}^{-1} \mathrm{~cm}^{-1}, \mathrm{FkpA} 8940 \mathrm{M}^{-1} \mathrm{~cm}^{-1}$, PpiD $24870 \mathrm{M}^{-1} \mathrm{~cm}^{-1}$, YfgM $8940 \mathrm{M}^{-1} \mathrm{~cm}^{-1}$ and Skp $5960 \mathrm{M}^{-1} \mathrm{~cm}^{-1}$. Monomer protein concentrations were adjusted to $50 \mu \mathrm{M}$ and the aliquoted proteins were flash frozen and stored at $-80^{\circ} \mathrm{C}$. Before experiments, the samples were thawed, centrifuged at $100.000 \mathrm{~g}, 4^{\circ} \mathrm{C}$ for $1 \mathrm{~h}$ to remove occasional aggregates and applied for SEC to match buffering conditions required for the conducted assays.

The lipase-specific foldase LipH lacking the TMD and bearing the N-terminal hexa-histidine tag was expressed heterologously as a soluble protein in E. coli BL21(DE3) using plasmid pEHTHis19 ${ }^{64}$. LipH was purified by IMAC and subsequent SEC in $100 \mathrm{mM} \mathrm{NaCl}, 200 \mu \mathrm{M}$ TCEP, $10 \%$ glycerol and $50 \mathrm{mM}$ Tris-HCl pH 8.0. Samples were flash-frozen and stored at $80{ }^{\circ} \mathrm{C}$. Directly before experiments $\mathrm{LipH}$ samples were thawed, centrifuged at $100.000 \mathrm{~g}, 4^{\circ} \mathrm{C}$ for $1 \mathrm{~h}$ and subject for SEC in $100 \mathrm{mM} \mathrm{NaCl}, 10 \%$ glycerol and $20 \mathrm{mM}$ Tris-HCl pH 8.0 unless other buffers are specified.

\section{Size exclusion chromatography combined with multi-angle light scattering}

SEC-MALS was employed to probe the oligomeric states of the isolated chaperones of $P$. aeruginosa. The purified proteins were concentrated to $2 \mathrm{mg} / \mathrm{mL}$ using centrifugal filters with either $3 \mathrm{kDa}$ or $30 \mathrm{kDa}$ cut-off (Amicon Ultra-0.5, Merck/Millipore) and the samples were centrifuged at $100,000 \mathrm{~g}, 4^{\circ} \mathrm{C}$ for $1 \mathrm{~h}$ to remove occasional aggregates. Subsequently, $80-200$ $\mu \mathrm{L}$ were injected on Superdex 200 Increase 10/300 GL column (Cytiva) connected to miniDAWN TREOS II light scattering device and Optilab-TrEX Ri-detector (Wyatt Technology Corp.). FkpA, SurA and PpiD were analysed in $50 \mathrm{mM} \mathrm{KCl,} 5 \mathrm{mM} \mathrm{MgCl}_{2}$ and $20 \mathrm{mM} \mathrm{HEPES-}$ $\mathrm{KOH} \mathrm{pH} \mathrm{7.4;} \mathrm{YfgM} \mathrm{in} 5 \mathrm{mM}$ glycine, $20 \mathrm{mM} \mathrm{NaCl}$ and $5 \mathrm{mM}$ Tris- $\mathrm{HCl} \mathrm{pH}$ 8.5; Skp in $100 \mathrm{mM}$ $\mathrm{NaCl}$ and $20 \mathrm{mM}$ Tris- $\mathrm{HCl} \mathrm{pH}$ 8.0, and LipH in $100 \mathrm{mM} \mathrm{NaCl}, 200 \mu \mathrm{M}$ TCEP and $50 \mathrm{mM}$ Tris$\mathrm{HCl} \mathrm{pH} \mathrm{8.0.} \mathrm{The} \mathrm{data} \mathrm{analysis} \mathrm{was} \mathrm{performed} \mathrm{with} \mathrm{ASTRA} \mathrm{7.3.2} \mathrm{software} \mathrm{(Wyatt} \mathrm{Technology}$ Corp.).

\section{Small-angle X-ray scattering}

SAXS data on Skp chaperone was collected using Xeuss 2.0 Q-Xoom system from Xenocs, equipped with a PILATUS3 R 300K detector (Dectris) and a GENIX 3D CU Ultra Low Divergence X-ray beam delivery system. The chosen sample-to-detector distance for the experiment was $0.55 \mathrm{~m}$, resulting in an achievable q-range of $0.05-6 \mathrm{~nm}^{-1}$. The measurement was carried out at $15^{\circ} \mathrm{C}$ with a protein concentration of $1.20 \mathrm{mg} / \mathrm{mL}$. Skp samples were injected in the Low Noise Flow Cell (Xenocs) via autosampler. 24 frames were collected with an 
exposure time of ten minutes per frame and the data was scaled to the absolute intensity against water.

All used programs for data processing were part of the ATSAS software package, version 3.0.3 65. Primary data reduction was performed with the program PRIMUS ${ }^{66}$. With the Guinier approximation, the forward scattering $I(0)$ and the radius of gyration $\left(R_{\mathrm{g}}\right)$ were determined. The program GNOM ${ }^{67}$ was used to estimate the maximum particle dimension $\left(D_{\max }\right)$ with the pairdistribution function $p(r)$. The ab initio reconstitution of the protein structure by dummy residues with P3 symmetry was performed using the GASBOR program ${ }^{39}$. The Skp trimer model was built using the cloud-based AlphaFold 2 Multimer algorithm ${ }^{40,41}$. The conformation analysis was performed using Ensemble Optimisation Method (EOM) using the default parameters (10000 models in the initial ensemble, native-like models, constant subtraction allowed) ${ }^{43,44}$.

\section{Lipase isolation}

The gene PA2862 encoding for the mature LipA was cloned into pET22b plasmid via $\mathrm{Ndel} / \mathrm{BamHI}$ restriction sites ${ }^{64}$ and the protein was expressed in E. coli BL21(DE3). Briefly, the overnight culture with LB ampicillin $(100 \mu \mathrm{g} / \mathrm{mL})$ grown at $37^{\circ} \mathrm{C}$ upon shaking at $180 \mathrm{rpm}$ used to inoculate $100 \mathrm{~mL}$ LB media. Cells were grown at $37^{\circ} \mathrm{C}$ upon shaking at $180 \mathrm{rpm}$ till reaching $\mathrm{OD}_{600}$ 0.6. LipA expression was induced by addition of $0.5 \mathrm{mM}$ IPTG to the culture and was conducted for $2 \mathrm{~h}$ at $37^{\circ} \mathrm{C}$. Cells were harvested by centrifugation at $4000 \mathrm{~g}, 4^{\circ} \mathrm{C}$ for $15 \mathrm{~min}$ and resuspended in $50 \mathrm{mM}$ Tris- $\mathrm{HCl}$ pH 7.0, 5 mM EDTA, $1 \mathrm{mM}$ TCEP, supplemented with $10 \mu \mathrm{g} / \mathrm{mL}$ DNAse I and $50 \mu \mathrm{g} / \mathrm{mL}$ lysozyme (buffer IB). The suspension was incubated at $20^{\circ} \mathrm{C}$ for $15 \mathrm{~min}$ and vortexed briefly, and the cells were lysed via sonication (ultrasonic homogenizer UP100H equipped with MS7 tip). The inclusion bodies were sedimented by centrifugation at $15000 \mathrm{~g}, 4^{\circ} \mathrm{C}$ for $10 \mathrm{~min}$ and suspended in the buffer IB for washing, followed by centrifugation. After repeating the procedure twice, the pellet was washed with $50 \mathrm{mM}$ Tris$\mathrm{HCl} \mathrm{pH} \mathrm{7.0.} \mathrm{The} \mathrm{inclusion} \mathrm{bodies} \mathrm{were} \mathrm{dissolved} \mathrm{in} 8 \mathrm{M}$ urea and $20 \mathrm{mM}$ Tris- $\mathrm{HCl} \mathrm{pH} 7.25$, and the insoluble material was removed via a centrifugation step $\left(21000 \mathrm{~g}, 10 \mathrm{~min}, 4^{\circ} \mathrm{C}\right)$. The protein purity was assessed by SDS-PAGE and subsequent staining (Quick Coomassie stain, Serva). LipA concentration was determined spectrophotometrically (extinction coefficient at $280 \mathrm{~nm}, \varepsilon_{280}=27515 \mathrm{M}^{-1} \mathrm{~cm}^{-1}$ ). LipA was aliquoted in reaction tubes (Low Protein Binding, Sarstedt), flash-frozen and stored at $-80^{\circ} \mathrm{C}$.

Optionally, LipA was fluorescently labelled to increase the detection efficiency in the sedimentation assay. LipA contains two endogenous cysteines in positions 183 and 235, which were targeted for site-specific fluorescent labelling. The urea-denatured LipA was incubated in 25-fold molar excess of fluorescein-5-maleimide (FM, Thermo Fisher Scientific) for $3 \mathrm{~h}$ at the ambient temperature. After the incubation, LipA was precipitated with $15 \%$ TCA for at least 
$1 \mathrm{~h}$ on ice. The precipitated proteins were sedimented via centrifugation at $21000 \mathrm{~g}, 4^{\circ} \mathrm{C}$ for $15 \mathrm{~min}$, and the supernatant was removed. The pellets were washed with $0.5 \mathrm{~mL}$ ice-cold acetone, and then repeatedly sedimented via centrifugation at $21000 \mathrm{~g}, 4^{\circ} \mathrm{C}$ for $10 \mathrm{~min}$. After drying at $37^{\circ} \mathrm{C}$, LipA-FM pellet was solubilised in $8 \mathrm{M}$ urea and $20 \mathrm{mM}$ Tris- $\mathrm{HCl} \mathrm{pH} \mathrm{7.25.} \mathrm{To}$ remove the remaining free dye, TCA precipitation and washing steps were repeated twice. The labelling efficiency of $\sim 150 \%$ was determined spectrophotometrically based on the absorbance at 280 and $495 \mathrm{~nm}$ and the molar extinction coefficients for LipA and FM, respectively. LipA-FM was visualised on SDS-PAGE via blue-light excitation and following Coomassie blue staining.

In vitro activity of the lipase

To measure the hydrolytic activity of LipA, equimolar concentrations of the foldase LipH in TGCG buffer ( $5 \mathrm{mM}$ Tris pH 9, $5 \mathrm{mM}$ glycine, $1 \mathrm{mM} \mathrm{CaCl}_{2}, 5 \%$ glycerol) and the urea-denatured LipA (8 M urea and $20 \mathrm{mM}$ Tris- $\mathrm{HCl} \mathrm{pH} 7.25$ ) were mixed together at concentration $1 \mu \mathrm{M}$ in TGCG buffer to form lipase:foldase complexes in reaction tubes (Low Protein Binding, Sarstedt). The complex formation was set for $15 \mathrm{~min}$ at $37^{\circ} \mathrm{C}$. After the incubation, $10 \mu \mathrm{L}$ of the sample were diluted 10-fold with the TGCG buffer in 96-well plates. For the substrate preparation, $10 \mathrm{mM}$ para-nitrophenyl butyrate, $\sim 1.76 \mu \mathrm{L}$, (pNPB, Merck/Sigma) were diluted from the stock solution in $1 \mathrm{~mL}$ acetonitrile. Immediately before starting the measurement, the substrate solution was diluted 10 -fold with $50 \mathrm{mM}$ triethanolamine $\mathrm{pH} 7.4$ and mixed. Subsequently, $100 \mu \mathrm{L}$ of the substrate solution was transferred to 96-well-plates with the preassembled LipA:LipH complex, so each well contained $0.5 \mathrm{mM}$ pNPB and $50 \mathrm{nM}$ LipA:LipH complex. For the negative control, LipA without LipH were treated the same as all other samples. To measure the autohydrolysis of the substrate, both LipA and LipH were omitted, but the corresponding buffers were added to $p N P B$. The hydrolysis of $p N P B$ to $p$ nitrophenolate and butyric acid was determined by measuring the absorbance of the liberated p-nitrophenolate at $410 \mathrm{~nm}$ over $3.5 \mathrm{~h}$ at $37^{\circ} \mathrm{C}$ on a plate reader (Infinite 200 pro, TECAN). Samples were shaken for 5 sec prior to each measurement. The hydrolytic activity of LipA was analysed by monitoring the hydrolysis based the p-nitrophenolate absorbance (as previously described) and by calculating the active LipA in $\mathrm{U} / \mathrm{mL}$ in the linear range of the reaction (first $15 \mathrm{~min}$ ), with the estimated molar extinction coefficient of p-nitrophenolate at $410 \mathrm{~nm}$ under the applied conditions of $12500 \mathrm{M}^{-1} \mathrm{~cm}^{-1} 68$. The light path length in the well was experimentally determined and was of $0.53-0.55 \mathrm{~cm}$ upon applied conditions.

When indicated, the experiments were performed in the presence of $\mathrm{NaCl}$ and calcium upon LipA:LipH assembly and during the substrate hydrolysis measurements. Prior to the experiments, $\mathrm{LipH}$ was transferred into $100 \mathrm{mM} \mathrm{NaCl}, 10 \%$ glycerol and $20 \mathrm{mM}$ Tris- $\mathrm{HCl} \mathrm{pH}$ 
8.0 by SEC, and the composition of the buffer for LipA:LipH assembly, as well as for hydrolysis measurements were adjusted. To study the effect of the periplasmic chaperones (Skp, YfgM, FkpA, SurA, PpiD) on the hydrolytic activity, the chaperones were transferred into either the TGCG buffer or $100 \mathrm{mM} \mathrm{NaCl}, 10 \%$ glycerol (v/v) and $20 \mathrm{mM}$ Tris-HCl pH 8.0 by SEC. The proteins, LipA and LipH, were added in equimolar concentrations $(1 \mu \mathrm{M})$ to form the complex, while the periplasmic chaperones were added in 5-fold molar excess. The complex formation and hydrolysis measurements were performed as described above. The activation of LipA by the periplasmic chaperones was also determined by adding LipA to the periplasmic chaperones at 1:5 molar ratio in the absence of $\mathrm{LipH}$. To probe the effect of the periplasmic chaperones on LipA aggregation prior the activation, $1 \mu \mathrm{M}$ LipA was incubated with individual periplasmic chaperones for $15 \mathrm{~min}$ at $37^{\circ} \mathrm{C}$. Afterwards, $1 \mu \mathrm{M}$ of $\mathrm{LipH}$ was added to the mixtures and incubated for $15 \mathrm{~min}$ at $37^{\circ} \mathrm{C}$. The measurements of $p$ NBP hydrolysis were performed as described above.

\section{Sedimentation analysis of LipA aggregation}

LipA aggregation at various conditions was probed by sedimentation assay. To improve the detection sensitivity and so facilitate the experiment at low lipase concentrations, site-specific fluorescent labelling of the lipase was introduced. The endogenous cysteines at positions 183 and 235 were conjugated with FM, as described above, so as little as $5 \mathrm{ng}$ LipA-FM could be detected via in-gel fluorescence imaging. The urea-denatured LipA-FM was diluted with the TGCG buffer from $150 \mu \mathrm{M}$ stock solution to $1.6 \mu \mathrm{M}$ and kept on ice protein in reaction tubes (Low Protein Binding, Sarstedt). The chaperones were transferred to $1.5 \mathrm{~mL}$ polypropylene reaction tubes containing $20 \mathrm{mM}$ Tris- $\mathrm{HCl} \mathrm{pH} 8.0$ and varying $\mathrm{NaCl}$ concentrations, to achieve the specific ionic strength indicated for each assay. The minimal ionic strength conditions were probed when using the TGCG buffer. $15.6 \mu \mathrm{L}$ of LipA-FM were added to the tube and mixed by pipetting, so the reactions contained $0.5 \mu \mathrm{M}$ LipA-FM and $5 \mu \mathrm{M}$ of individual chaperones in the total volume of $50 \mu \mathrm{L}$. For the dimeric FkpA and trimeric Skp, the monomer concentrations were $10 \mu \mathrm{M}$ and $15 \mu \mathrm{M}$, respectively. The LipA-specific foldase LipH was used in the equimolar ratio to the lipase (final concentration $0.5 \mu \mathrm{M}$ ). The reaction tubes were incubated at $37^{\circ} \mathrm{C}$ for $15 \mathrm{~min}$ to promote LipA aggregation and the samples were then centrifuged ( $21000 \mathrm{~g}, 15 \mathrm{~min}$, $4{ }^{\circ} \mathrm{C}$ ) to sediment the aggregates. To avoid disturbing the pellets, $40 \mu \mathrm{L}$ of each supernatant fraction were transferred to new $1.5 \mathrm{~mL}$ tubes. The remaining material contained the aggregated LipA as a pellet and also $10 \mu \mathrm{L}$ of the supernatant fraction. Both samples were precipitated by adding $100 \mu \mathrm{L}$ of $20 \%$ TCA and incubating for $15 \mathrm{~min}$ on ice. The precipitated proteins were pelleted upon centrifugation at $21000 \mathrm{~g}, 4^{\circ} \mathrm{C}$ for $10 \mathrm{~min}$, TCA was removed, and the samples were washed, as described above. Further, $15 \mu \mathrm{L}$ of $2 \mathrm{x}$ reducing SDS-PAGE sample buffer were used to wash the tube walls, and $5 \mu \mathrm{L}$ of the sample were loaded on SDS- 
PAGE and in-gel fluorescence was recorded. The signal was quantified by ImageQuant software (Cytiva). The background was subtracted using the local average algorithm. The signals of the supernatant $\left(I_{\mathrm{sol}}\right)$ represent the soluble fraction of LipA and correspond to $80 \%$ of the total soluble LipA. The value was used then to calculate the actual signal intensities of the soluble $\left(I_{\text {sol, corr }}\right)$ and aggregated $\left(I_{\text {agg, corr }}\right)$ LipA, as:

$$
\begin{gathered}
I_{\text {sol,corr }}=1.25 * I_{\text {sol }} \\
I_{\text {agg,corr }}=I_{\text {agg }}-0.25 * I_{\text {sol }}
\end{gathered}
$$

where $I_{\text {agg }}$ is the signal measured for the aggregated LipA and the remaining $10 \mu \mathrm{L}$ of the supernatant. The soluble fraction of LipA was calculated as a ratio:

$$
\frac{I_{\text {sol,corr }}}{I_{\text {sol }}+I_{\text {agg }}}
$$

Each assay was carried out in triplicates.

\section{Amyloid-specific ThT fluorescence}

Thioflavin T (ThT, Merck/Sigma-Aldrich) was dissolved to the concentration of $100 \mu \mathrm{M}$ in the buffer TGCG, and the solution was kept on ice. Immediately prior to the experiment, ThT was diluted with the TGCG buffer to $10 \mu \mathrm{M}$ and mixed with $0.5 \mu \mathrm{M}$ urea-denatured LipA and $5 \mu \mathrm{M}$ chaperones. For the dimeric FkpA and trimeric Skp, the monomer concentrations were $10 \mu \mathrm{M}$ and $15 \mu \mathrm{M}$, respectively. The total volume was set to $65 \mu \mathrm{L}$ and the reaction was carried out at room temperature in reaction tubes (Low Protein Binding, Sarstedt). For the control experiments, containing either the chaperones or LipA, the reaction volume was adjusted to $65 \mu \mathrm{L}$ with an appropriate buffer. After incubation at $37{ }^{\circ} \mathrm{C}$ for $15 \mathrm{~min}$, each reaction was transferred into a quartz cuvette for measuring ThT fluorescence at the fluorescence spectrophotometer (Fluorolog 3, Horiba Scientific). The excitation wavelength was set at 450 $\mathrm{nm}$, and the emission spectra were recorded from 467 to $520 \mathrm{~nm}$. ThT fluorescence intensity at $485 \mathrm{~nm}$ was used to evaluate and compare LipA aggregation between samples. Each measurement was carried out in independent triplicates.

\section{Microscale thermophoresis}

MST was used to monitor interactions of Skp from $P$. aeruginosa with FM-labelled LipA $A_{F 144 E}$. LipA $_{\text {F144E }}$ was diluted to $100 \mathrm{nM}$ in the TGCG buffer supplemented with $0.05 \%$ Tween 20 and kept on ice protected from light. For the MST measurement, $10 \mu \mathrm{l}$ of $50 \mathrm{nM}$ LipA were mixed with Skp ranging from to $2.3 \mathrm{nM}$ to $18.5 \mu \mathrm{M}$ in a $0.5 \mathrm{~mL}$ reaction tube (Low Protein Binding, 
Sarstedt). LipA:Skp samples were incubated for $15 \mathrm{~min}$ at $22{ }^{\circ} \mathrm{C}$ in the dark, then loaded into Premium-type capillaries and analysed in Monolith NT.115 instrument (NanoTemper Technologies, Munich, Germany). The MST power was set to $80 \%$ and the LED power in the blue channel was set to $60 \%$. The thermophoresis was detected by the normalised fluorescence time traces for 30 seconds with 5 seconds delay and 5 seconds for recovery. The putative LipA aggregation at the capillary surface was controlled by recording the fluorescence intensity profiles of individual capillaries before and after the experiment (time difference approx. 1 hour). The data was evaluated by NT Analysis software (NanoTemper Technologies, Munich, Germany). Each sample was analysed twice, and the measurement were performed in independent triplicates.

\section{Transmission electron microscopy}

TEM was utilized to visualize the formation of LipA aggregates. All buffers were filtered with $0.1 \mu \mathrm{m}$ filters (Whatman Puradisc 0.1 micron). Denatured LipA was diluted to $300-500 \mu \mathrm{M}$ in $20 \mathrm{mM}$ Tris- $\mathrm{HCl} \mathrm{pH} 7.25$ and $8 \mathrm{M}$ urea. In case of TEM analysis of LipA in urea, the protein was further diluted in $20 \mathrm{mM}$ Tris- $\mathrm{HCl} \mathrm{pH} 7.25$ and $8 \mathrm{M}$ urea. For urea-free measurements, LipA was diluted to 3-20 $\mu \mathrm{M}$ in either TGCG buffer or in $150 \mathrm{mM} \mathrm{NaCl}, 10 \%$ glycerol and 20 $\mathrm{mM}$ Tris- $\mathrm{HCl} \mathrm{pH}$ 8.0. Samples containing Skp or $\mathrm{LipH}$ were prepared in $20 \mathrm{mM}$ Tris- $\mathrm{HCl} \mathrm{pH}$ 8.0, $150 \mathrm{mM} \mathrm{NaCl}$ and $10 \%$ glycerol to promote lipase aggregation and visualize the antiaggregating effect of the chaperones. LipA:LipH samples contained $5 \mu \mathrm{M}$ LipA and $15 \mu \mathrm{M} \mathrm{LipH}$ (molar ratio 1:3) and LipA:Skp 3 samples contained $3 \mu \mathrm{M} \mathrm{LipA}$ and $15 \mu \mathrm{M} \mathrm{Skp} 3$ (molar ratio 1:5). All samples were incubated for $15 \mathrm{~min}$ at $37^{\circ} \mathrm{C}$ and used for grid preparation on a carboncoated copper grid. $3 \mu \mathrm{L}$ of sample were added on top of the grid incubated for $1 \mathrm{~min}$ at the ambient temperature. Excess liquid was removed using filter paper. For negative staining, the grid was incubated in $2 \%$ uranyl acetate (solution in distilled water $\mathrm{pH} 4.3$ ) for $1 \mathrm{~min}$ in the dark. Afterwards, excess liquid was removed. Grids were dried at the ambient temperature for at least 15 min prior TEM imaging imaging. TEM images were acquired the Zeiss EM902 operating at $80 \mathrm{KV}$ using a slow-scan CCD-Camera (Typ 7899 inside) controlled by the imaging software ImageSP (SYSPROG, TRS) and prepared using the image processing software "Fiji" 69 . 


\section{Data availability}

We uploaded the SAXS data to the Small Angle Scattering Biological Data Bank (SASBDB; www.sasbdb.org) with the accession code SASDNM5.

\section{Contributions}

$\mathrm{AP}$ and $\mathrm{MBu}$ carried out cloning, protein expression and isolation, and biochemical and fluorescence-based experiments; JR and SHJS carried out SAXS measurements and structural characterization of chaperones; EH carried out SEC-MALS analysis; MBä carried out TEM imaging; LS, KEJ, FK, SHJS and AK supervised the research. AP and AK wrote the manuscript with help of all co-authors.

\section{Acknowledgements}

The research was supported by the German Research Foundation (Deutsche Forschungsgemeinschaft, DFG) via the Collaborative Research Centre 1208 "Identity and Dynamics of Membrane Systems - from Molecules to Cellular Functions" (project 267205415, sub-projects A1, A2, A10, and Z02). The Center for Structural Studies is funded by DFG, projects 417919780 and INST 208/761-1 FUGG. Center of Advanced imaging is funded by DFG, project 284074525. Our special thanks go to Jessica Hausmann and Stefanie Weidtkamp-Peters for their kind support on TEM.

\section{Competing interests}

The authors declare no competing interests. 
bioRxiv preprint doi: https//doi.org/10.1101/2022.03.01.482502 this version posted March 1.2022. The copyright holder for this preprint (which was not certified by peer review) is the author/funder, who has granted bioRxiv a license to display the preprint in perpetuity. It is made available under aCC-BY-ND 4.0 International license.

\section{References}

1. Sadikot, R. T., Blackwell, T. S., Christman, J. W. \& Prince, A. S. Pathogen-Host Interactions in Pseudomonas aeruginosa Pneumonia. Am. J. Respir. Crit. Care Med. 171, 1209-1223 (2005).

2. Driscoll, J. A., Brody, S. L. \& Kollef, M. H. The epidemiology, pathogenesis and treatment of Pseudomonas aeruginosa infections. Drugs 67, 351-368 (2007).

3. Strateva, T. \& Mitov, I. Contribution of an arsenal of virulence factors to pathogenesis of Pseudomonas aeruginosa infections. Ann. Microbiol. 61, 717-732 (2011).

4. Lazdunski, A., Guzzo, J., Filloux, A., Bally, M. \& Murgier, M. Secretion of extracellular proteins by Pseudomonas aeruginosa. Biochimie 72, 147-156 (1990).

5. Jaeger, K.-E. et al. Bacterial lipases. FEMS Microbiol. Rev. 15, 29-63 (1994).

6. Nardini, M., Lang, D. A., Liebeton, K., Jaeger, K.-E. \& Dijkstra, B. W. Crystal structure of Pseudomonas aeruginosa lipase in the open conformation. The prototype for family I.1 of bacterial lipases. J. Biol. Chem. 275, 31219-31225 (2000).

7. König, B., Jaeger, K. E., Sage, A. E., Vasil, M. L. \& König, W. Role of Pseudomonas aeruginosa lipase in inflammatory mediator release from human inflammatory effector cells (platelets, granulocytes, and monocytes). Infect. Immun. 64, 3252-3258 (1996).

8. Tielen, P. et al. Interaction between extracellular lipase LipA and the polysaccharide alginate of Pseudomonas aeruginosa. BMC Microbiol. 13, 159 (2013).

9. Tsirigotaki, A., De Geyter, J., Šoštarić, N., Economou, A. \& Karamanou, S. Protein export through the bacterial Sec pathway. Nat. Rev. Microbiol. 15, 21-36 (2017).

10. Douzi, B., Ball, G., Cambillau, C., Tegoni, M. \& Voulhoux, R. Deciphering the Xcp Pseudomonas aeruginosa type II secretion machinery through multiple interactions with substrates. J. Biol. Chem. 286, 40792-40801 (2011).

11. El Khattabi, M., Van Gelder, P., Bitter, W. \& Tommassen, J. Role of the lipase-specific foldase of Burkholderia glumae as a steric chaperone. J. Biol. Chem. 275, 2688526891 (2000).

12. Pauwels, K., Sanchez del Pino, M. M., Feller, G. \& Van Gelder, P. Decoding the Folding of Burkholderia glumae Lipase: Folding Intermediates En Route to Kinetic Stability. PLoS One 7, e36999 (2012).

13. Hobson, A. H. et al. Activation of a bacterial lipase by its chaperone. Proc. Natl. Acad. Sci. U. S. A. 90, 5682-5686 (1993).

14. Rosenau, F., Tommassen, J. \& Jaeger, K.-E. Lipase-specific foldases. ChemBioChem 5, 152-161 (2004).

15. Pauwels, K. et al. Structure of a membrane-based steric chaperone in complex with its lipase substrate. Nat. Struct. Mol. Biol. 13, 374-375 (2006).

16. Viegas, A. et al. Structural and dynamic insights revealing how lipase binding domain MD1 of Pseudomonas aeruginosa foldase affects lipase activation. Sci. Rep. 10, 3578 (2020).

17. Verma, N., Dollinger, P., Kovacic, F., Jaeger, K.-E. \& Gohlke, H. The MembraneIntegrated Steric Chaperone Lif Facilitates Active Site Opening of Pseudomonas aeruginosa Lipase A. J. Comput. Chem. 41, 500-512 (2020). 
bioRxiv preprint doi: https://doi.org/10.1101/2022.03.01.482502 this version posted March 1.2022. The copyriaht holder for this preprint (which was not certified by peer review) is the author/funder, who has granted bioRxiv a license to display the preprint in perpetuity. It is made available under aCC-BY-ND 4.0 International license.

18. Frenken, L. G. J., de Groot, A., Tommassen, J. \& Verrips, C. T. Role of the lipB gene product in the folding of the secreted lipase of Pseudomonas glumae. Mol. Microbiol. 9, 591-599 (1993).

19. Rollauer, S. E., Sooreshjani, M. A., Noinaj, N. \& Buchanan, S. K. Outer membrane protein biogenesis in Gram-negative bacteria. Philos. Trans. B 370, 1-10 (2015).

20. De Geyter, J. et al. Protein folding in the cell envelope of Escherichia coli. Nat. Microbiol. 1, 16107 (2016).

21. Masuda, T., Saito, N., Tomita, M. \& Ishihama, Y. Unbiased quantitation of Escherichia coli membrane proteome using phase transfer surfactants. Mol. Cell. Proteomics 8 , 2770-2777 (2009).

22. Sachelaru, I., Petriman, N. A., Kudva, R. \& Koch, H. G. Dynamic interaction of the Sec translocon with the chaperone PpiD. J. Biol. Chem. 289, 21706-21715 (2014).

23. Götzke, H. et al. YfgM is an ancillary subunit of the SecYEG translocon in Escherichia coli. J. Biol. Chem. 289, 19089-19097 (2014).

24. Jarchow, S., Lück, C., Görg, A. \& Skerra, A. Identification of potential substrate proteins for the periplasmic Escherichia coli chaperone Skp. Proteomics 8, 4987-4994 (2008).

25. Purdy, G. E., Fisher, C. R. \& Payne, S. M. IcsA Surface Presentation in Shigella flexneri Requires the Periplasmic Chaperones DegP, Skp, and SurA. J. Bacteriol. 189, 5566-5573 (2007).

26. Entzminger, K. C., Chang, C., Myhre, R. O., McCallum, K. C. \& Maynard, J. A. The Skp Chaperone Helps Fold Soluble Proteins in Vitro by Inhibiting Aggregation. Biochemistry 51, 4822-4834 (2012).

27. Narayanan, N., Khan, M. \& Chou, C. P. Enhancing functional expression of heterologous Burkholderia lipase in Escherichia coli. Mol. Biotechnol. 47, 130-143 (2011).

28. Fernandez-Escamilla, A. M., Rousseau, F., Schymkowitz, J. \& Serrano, L. Prediction of sequence-dependent and mutational effects on the aggregation of peptides and proteins. Nat. Biotechnol. 22, 1302-1306 (2004).

29. Rashno, F., Khajeh, K., Dabirmanesh, B., Sajedi, R. H. \& Chiti, F. Insight into the aggregation of lipase from Pseudomonas sp. using mutagenesis: Protection of aggregation prone region by adoption of $\alpha$-helix structure. Protein Eng. Des. Sel. 31, 419-426 (2018).

30. Biancalana, M. \& Koide, S. Molecular mechanism of Thioflavin-T binding to amyloid fibrils. Biochim. Biophys. Acta - Proteins Proteomics 1804, 1405-1412 (2010).

31. Grandjean Lapierre, S. et al. Cystic fibrosis respiratory tract salt concentration: An Exploratory Cohort Study. Medicine (Baltimore). 96, (2017).

32. Dwyer, R. S., Malinverni, J. C., Boyd, D., Beckwith, J. \& Silhavy, J. Folding LacZ in the Periplasm of Escherichia coli. J. Bacteriol. 196, 3343-3350 (2014).

33. Saul, F. A. et al. Structural and Functional Studies of FkpA from Escherichia coli, a cis/trans Peptidyl-prolyl Isomerase with Chaperone Activity. J. Mol. Biol. 335, 595-608 (2004).

34. Walton, T. A. \& Sousa, M. C. Crystal Structure of Skp, a Prefoldin-like Chaperone that 
bioRxiv preprint doi: https:/doi.org/10.1101/2022.03.01.482502 this version posted March 1.2022. The copvriaht holder for this preprint (which was not certified by peer review) is the author/funder, who has granted bioRxiv a license to display the preprint in perpetuity. It is made available under aCC-BY-ND 4.0 International license.

Protects Soluble and Membrane Proteins from Aggregation. Mol. Cell 15, 367-374 (2004).

35. Bitto, E. \& McKay, D. B. Crystallographic structure of SurA, a molecular chaperone that facilitates folding of outer membrane porins. Structure 10, 1489-1498 (2002).

36. Matern, Y., Barion, B. \& Behrens-Kneip, S. PpiD is a player in the network of periplasmic chaperones in Escherichia coli. BMC Microbiol. 10, 251 (2010).

37. Korndörfer, I. P., Dommel, M. K. \& Skerra, A. Structure of the periplasmic chaperone Skp suggests functional similarity with cytosolic chaperones despite differing architecture. Nat. Struct. Mol. Biol. 11, 1015-1020 (2004).

38. Holdbrook, D. A. et al. A Spring-Loaded Mechanism Governs the Clamp-like Dynamics of the Skp Chaperone. Structure 25, 1079-1088 (2017).

39. Svergun, D. I., Petoukhov, M. V. \& Koch, M. H. J. Determination of domain structure of proteins from x-ray solution scattering. Biophys. J. 80, 2946-2953 (2001).

40. Jumper, J. et al. Highly accurate protein structure prediction with AlphaFold. Nature 596, 583-589 (2021).

41. Evans, R. et al. Protein complex prediction with AlphaFold-Multimer. (2021). doi:https://doi.org/10.1101/2021.10.04.463034

42. Svergun, D., Barberato, C. \& Koch, M. H. CRYSOL - A program to evaluate X-ray solution scattering of biological macromolecules from atomic coordinates. J. Appl. Crystallogr. 28, 768-773 (1995).

43. Bernadó, P., Mylonas, E., Petoukhov, M. V., Blackledge, M. \& Svergun, D. I. Structural Characterization of Flexible Proteins Using Small-Angle X-ray Scattering. J. Am. Chem. Soc. 129, 5656-5664 (2007).

44. Tria, G., Mertens, H. D. T., Kachala, M. \& Svergun, D. I. Advanced ensemble modelling of flexible macromolecules using X-ray solution scattering. IUCrJ 2, 207217 (2015).

45. Qu, J., Mayer, C., Behrens, S., Holst, O. \& Kleinschmidt, J. H. The Trimeric Periplasmic Chaperone Skp of Escherichia coli Forms 1:1 Complexes with Outer Membrane Proteins via Hydrophobic and Electrostatic Interactions. J. Mol. Biol. 374, 91-105 (2007).

46. Schiffrin, B. et al. Skp is a multivalent chaperone of outer-membrane proteins. Nat. Struct. Mol. Biol. 23, 786-793 (2016).

47. Pan, S., Yang, C. \& Zhao, X. S. Affinity of Skp to OmpC revealed by single-molecule detection. Sci. Rep. 10, 14871 (2020).

48. Mas, G. et al. Regulation of chaperone function by coupled folding and oligomerization. Sci. Adv. 6, eabc5822 (2020).

49. Hartl, F. U., Bracher, A. \& Hayer-Hartl, M. Molecular chaperones in protein folding and proteostasis. Nature 475, 324-332 (2011).

50. Stull, F., Betton, J.-M. \& Bardwell, J. C. A. Periplasmic Chaperones and Prolyl Isomerases. EcoSal Plus 8, (2018).

51. Rashno, F. et al. Very rapid amyloid fibril formation by a bacterial lipase in the absence of a detectable lag phase. Biochim. Biophys. Acta - Proteins Proteomics 1865, 652-663 (2017). 
bioRxiv preprint doi: https//doi.org/10.1101/2022.03.01.482502. this version posted March 1.2022. The copyriaht holder for this preprint (which was not certified by peer review) is the author/funder, who has granted bioRxiv a license to display the preprint in perpetuity. It is made available under aCC-BY-ND 4.0 International license.

52. Khan, F. I. et al. The lid domain in lipases: Structural and functional determinant of enzymatic properties. Front. Bioeng. Biotechnol. 5, 16 (2017).

53. Kirchner, S. et al. Use of artificial sputum medium to test antibiotic efficacy against Pseudomonas aeruginosa in conditions more relevant to the cystic fibrosis lung. $\mathrm{J}$. Vis. Exp. 1-8 (2012). doi:10.3791/3857

54. Lee, S. A. et al. General and condition-specific essential functions of Pseudomonas aeruginosa. Proc. Natl. Acad. Sci. U. S. A. 112, 5189-5194 (2015).

55. Burmann, B. M., Wang, C. \& Hiller, S. Conformation and dynamics of the periplasmic membrane-protein-chaperone complexes OmpX-Skp and tOmpA-Skp. Nat. Struct. Mol. Biol. 20, 1265-1272 (2013).

56. Denoncin, K., Schwalm, J., Vertommen, D., Silhavy, T. J. \& Collet, J. F. Dissecting the Escherichia coli periplasmic chaperone network using differential proteomics.

Proteomics 12, 1391-1401 (2012).

57. He, L. \& Hiller, S. Common Patterns in Chaperone Interactions with a Native Client Protein. Angew. Chemie - Int. Ed. 57, 5921-5924 (2018).

58. Combs, A. N. \& Silhavy, T. J. The sacrificial adaptor protein Skp functions to remove stalled substrates from the $\beta$-barrel assembly machine. Proc. Natl. Acad. Sci. U. S. A. 119, e2114997119 (2022).

59. Li, G. et al. Single-Molecule Detection Reveals Different Roles of Skp and SurA as Chaperones. ACS Chem. Biol. 13, 1082-1089 (2018).

60. Wagner, J. K., Heindl, J. E., Gray, A. N., Jain, S. \& Goldberg, M. B. Contribution of the Periplasmic Chaperone Skp to Efficient Presentation of the Autotransporter IcsA on the Surface of Shigella flexneri. J. Bacteriol. 191, 815-821 (2009).

61. Klein, K. et al. Deprivation of the Periplasmic Chaperone SurA Reduces Virulence and Restores Antibiotic Susceptibility of Multidrug-Resistant Pseudomonas aeruginosa. Front. Microbiol. 10, (2019).

62. Petersen, T. N., Brunak, S., Von Heijne, G. \& Nielsen, H. SignalP 4.0: Discriminating signal peptides from transmembrane regions. Nat. Methods 8, 785-786 (2011).

63. Krogh, A., Larsson, B., Von Heijne, G. \& Sonnhammer, E. L. L. Predicting Transmembrane Protein Topology with a Hidden Markov Model : Application to Complete Genomes. J. Mol. Biol. 305, 567-580 (2001).

64. Hausmann, S., Wilhelm, S., Jaeger, K.-E. \& Rosenau, F. Mutations towards enantioselectivity adversely affect secretion of Pseudomonas aeruginosa lipase. FEMS Microbiol. Lett. 282, 65-72 (2008).

65. Manalastas-Cantos, K. et al. ATSAS 3.0: expanded functionality and new tools for small-angle scattering data analysis. J. Appl. Crystallogr. 54, 343-355 (2021).

66. Konarev, P. V, Volkov, V. V, Sokolova, A. V, Koch, M. H. J. \& Svergun, D. I. PRIMUS: a Windows PC-based system for small-angle scattering data analysis. J. Appl. Crystallogr. 36, 1277-1282 (2003).

67. Svergun, D. I. Determination of the regularization parameter in indirect-transform methods using perceptual criteria. J. Appl. Crystallogr. 25, 495-503 (1992).

68. Filloux, A. \& Walker, J. M. Pseudomonas Methods and Protocols. in (eds. Filloux, A. \& Ramos, J.-L.) 1149, 293-301 (Springer New York, 2014). 
bioRxiv preprint doi: https://doi.org/10.1101/2022 03 01.482502. this version posted March 1 2022. The copyright holder for this preprint

(which was not certified by peer review) is the author/funder, who has granted bioRxiv a license to display the preprint in perpetuity. It is made available under aCC-BY-ND 4.0 International license.

69. Schindelin, J. et al. Fiji: An open-source platform for biological-image analysis. Nat. Methods 9, 676-682 (2012). 


\section{Figures}
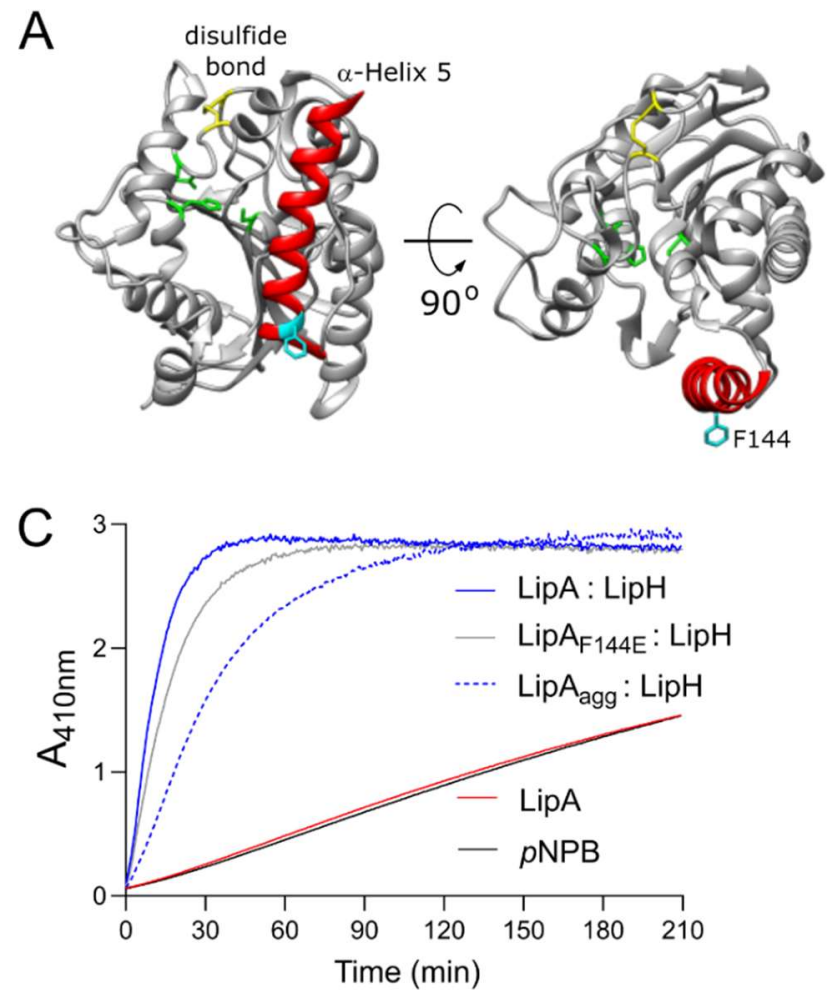
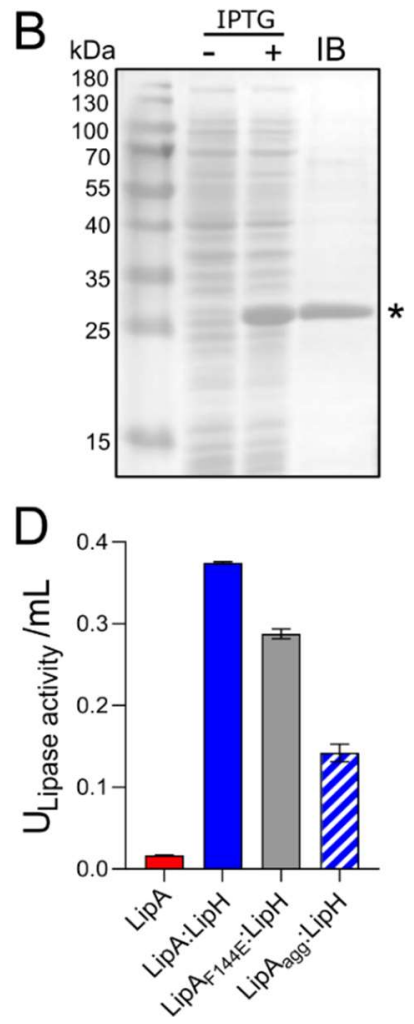

Figure 1. Lipase A from Pseudomonas aeruginosa PAO1.

A) Structure of the lipase LipA (PDB ID: 1EX9). The catalytic triad of Ser-82, Asp-229 and His251 is shown in green, the disulfide bridge between Cys-183 and Cys-235 is shown in yellow. The $\alpha$-helix 5 forming the lid domain is shown in red, with the residue F144 in cyan.

B) LipA expression and purification visualized on SDS-PAGE. Cell lysates prior adding IPTG (“-") and after 2 hours of expression ("+") are shown. Lane "IB": isolated inclusion bodies. LipA band is indicated with asterisk.

C) Lipase activity in vitro mediated by the foldase LipH. Change in absorbance at $410 \mathrm{~nm}$ is associated with hydrolysis of the substrate, para-nitrophenyl butyrate ( $p N P B)$. Once being folded in presence of $\mathrm{LipH}$, the wild-type LipA and the mutant LipA ${ }_{F 144 \mathrm{E}}$ are able to hydrolyse pNPB (blue and grey solid traces, respectively). Pre-incubation of the wild-type lipase in the absence of $\mathrm{LipH}$ ( $\mathrm{LipA}_{\text {agg }}$ ) leads to the partial inhibition of hydrolysis (blue dashed trace). LipA activity in the absence of LipH (red trace), and the autohydrolysis of the substrate (black trace) are indicated.

D) Quantification of the hydrolytic activity of LipA. The lipase activity was calculated based on the colorimetric signal after $15 \mathrm{~min}$ of $p$ NPB hydrolysis (panel $\mathrm{C}$ ). The assays were performed in technical triplicates, the mean values and the standard deviations (SD) are shown. 

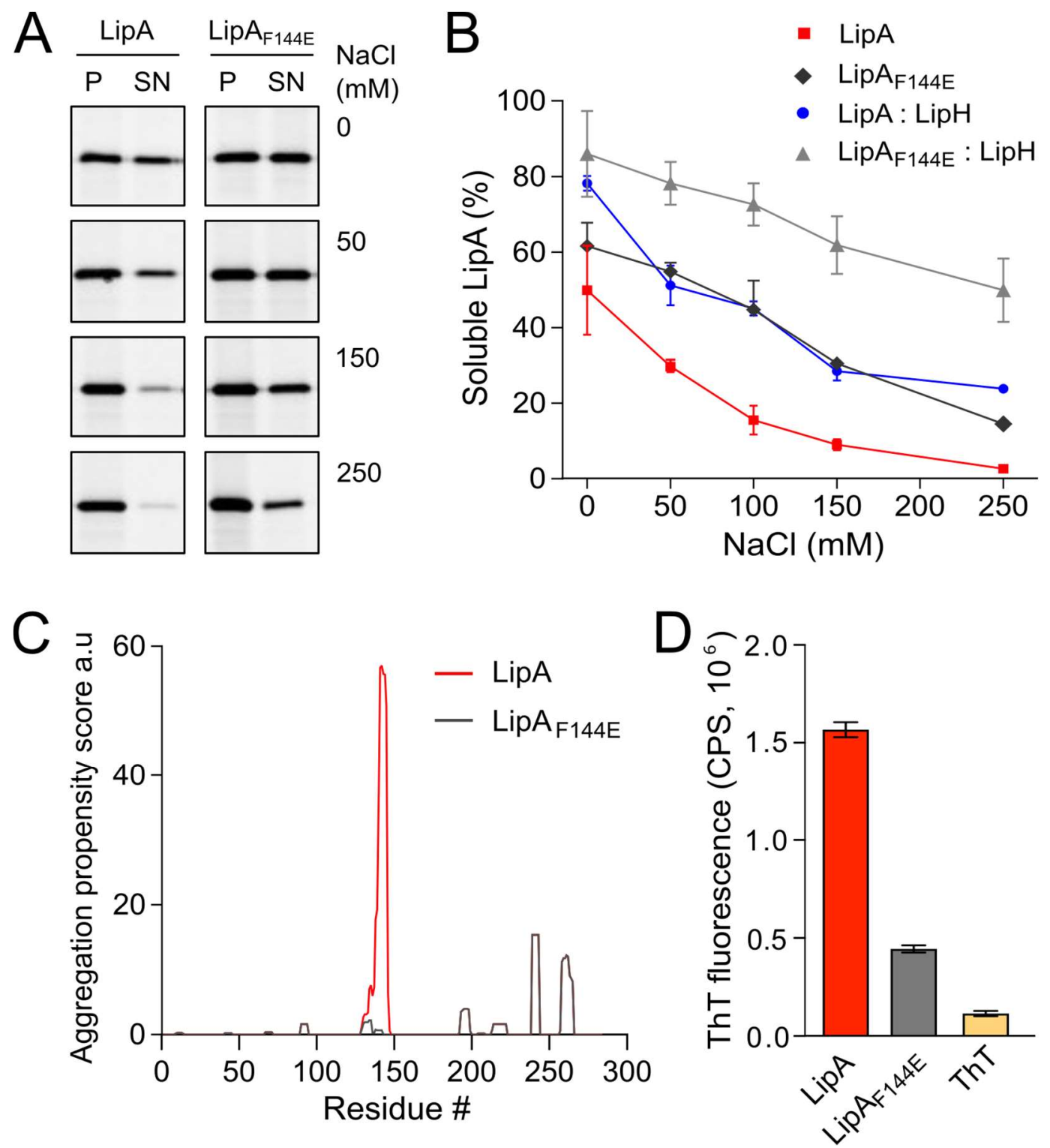

Figure 2. LipA aggregation propensity is sensitive to the environment and the structure of the lid domain.

A) SDS-PAGE of the aggregated and soluble LipA variants separated into the pellet $(P)$ and the supernatant $(\mathrm{SN})$ fractions, respectively, upon centrifugation. The concentrations of $\mathrm{NaCl}$ in the buffer are indicated. For the in-gel fluorescence detection, the lipases were labelled with fluorescein-5-maleimide.

B) Quantification of the soluble LipA at various conditions. The fraction of the soluble wild-type LipA and the mutant LipA ${ }_{F 144 E}$ at various salt concentrations and, optionally, in presence of LipH was calculated from SDS-PAGE (panel A). The assays were performed in technical triplicates, the mean values and SD are shown.

C) Sequence-based prediction of LipA aggregation propensity by TANGO algorithm ${ }^{28}$. Profiles for the $\beta$-aggregation propensity scores of the wild-type LipA (red) and the mutant LipA $A_{F 144 E}$ 
bioRxiv preprint doi: https://doi.org/10.1101/2022.03 01.482502· this version posted March 1, 2022. The copyright holder for this preprint (which was not certified by peer review) is the author/funder, who has granted bioRxiv a license to display the preprint in perpetuity. It is made available under aCC-BY-ND 4.0 International license.

(grey) indicate the aggregation-prone regions within the polypeptide chain. The aggregation propensity of the wild-type LipA is dominated by the $\alpha$-helix 5 that forms the lid domain.

D) LipA aggregation is associated with the formation of $\beta$-structured amyloid-like aggregates. The intensity of the amyloid-sensitive ThT fluorescence at $485 \mathrm{~nm}$ was measured in the presence of either the wild-type LipA (red), the mutant LipA $\mathrm{F}_{\mathrm{F} 14 \mathrm{E}}$ (grey), or the dye alone (yellow). The assays were performed in technical triplicates, the mean values and SD are shown. 
A
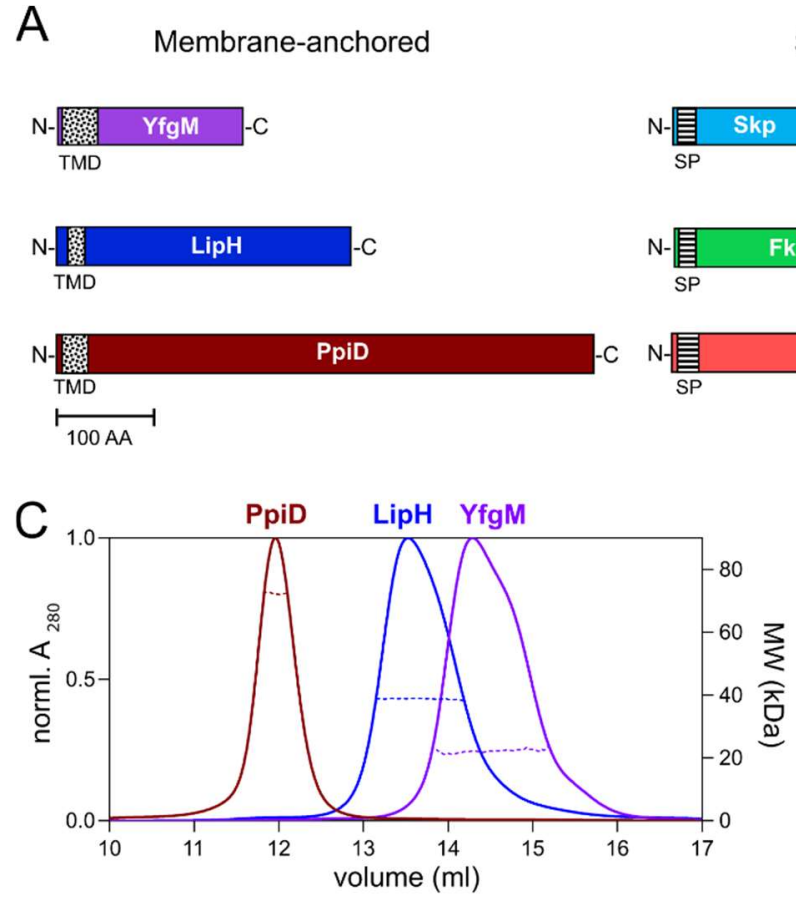

Soluble
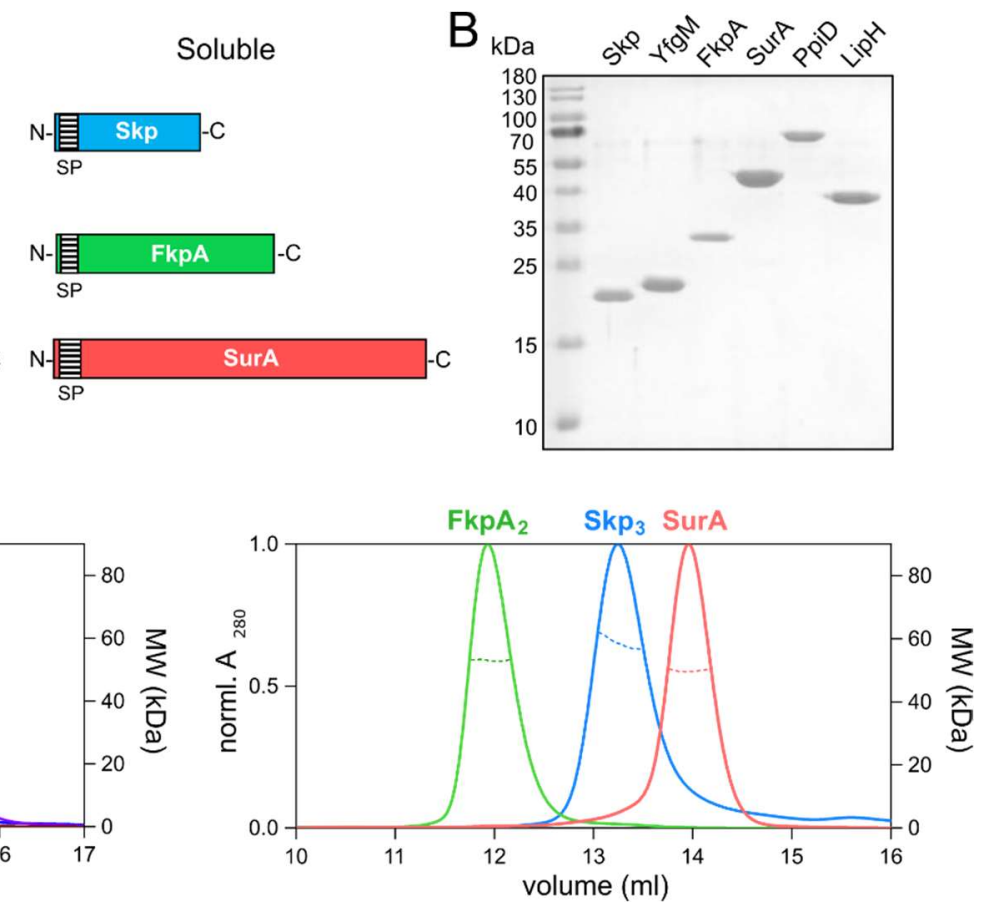

Figure 3. Periplasmic chaperones of $P$. aeruginosa PAO1

A) Schematic overview of the periplasmic chaperones of $P$. aeruginosa PAO1. The predicted transmembrane domains (TMD, black-dotted) and the signal peptides (SP, black-ruled) were removed to express the soluble chaperones. Scale bar: 100 amino acid residues (AA).

B) SDS-PAGE of the isolated periplasmic chaperones of $P$. aeruginosa.

C) SEC-MALS analysis of the periplasmic chaperones to determine the oligomeric states in solution. Solid traces represent the absorbance at $280 \mathrm{~nm}$, dashed traces indicate the molecular weights ( $y$-axis on the right) calculated from the light scattering. The analysis reveals dimers of $\mathrm{FkpA}\left(\mathrm{FkpA}_{2}\right)$ and trimers of $\mathrm{Skp}\left(\mathrm{Skp}_{3}\right)$, while SurA, YfgM, PpiD and LipH are monomeric in solution. 

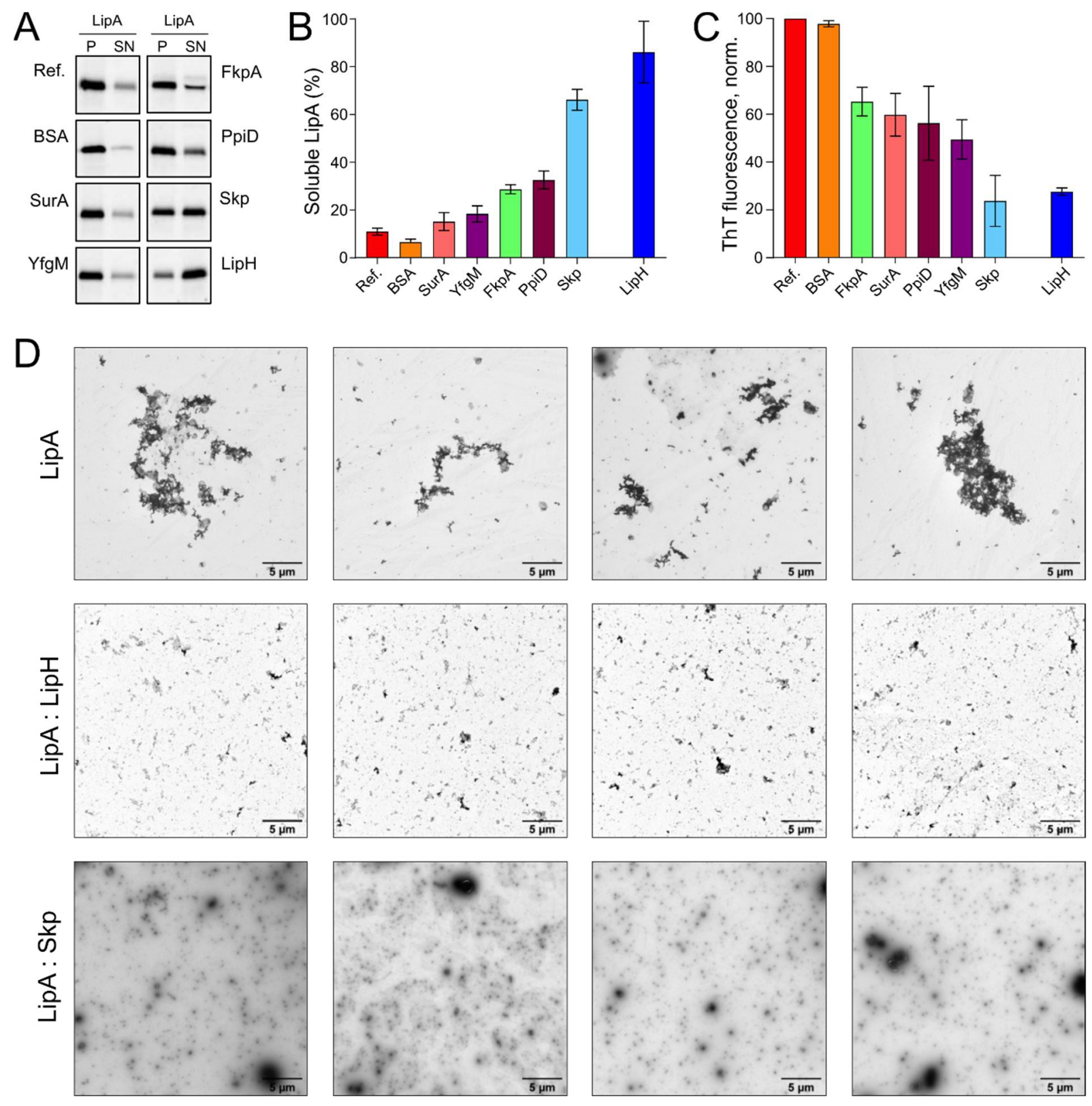

Figure 4. The periplasmic chaperone Skp rescues LipA from aggregation.

A) LipA solubility in the presence of the periplasmic chaperones. The aggregated and soluble LipA fractions are separated in pellet (P) and supernatant (SN) fractions in the sedimentation assay and visualized on SDS-PAGE via in-gel fluorescence. The supplemented chaperones are indicated. Bovine serum albumin (BSA) was used as a negative control. LipA in absence of chaperones is indicated as "Ref.".

B) Quantification of the soluble LipA in the presence of the periplasmic chaperones from SDSPAGE (panel A). The assays were performed in technical triplicates, the mean values and SD are shown. 
bioRxiv preprint doi: https://doi.org/10.1101/2022 03.01.482502; this version posted March 1, 2022. The copyright holder for this preprint (which was not certified by peer review) is the author/funder, who has granted bioRxiv a license to display the preprint in perpetuity. It is made available under aCC-BY-ND 4.0 International license.

C) The periplasmic chaperones suppress formation of LipA $\beta$-structured aggregates. ThT fluorescence was recorded for the wild-type LipA in the presence of the periplasmic chaperones and normalized to the fluorescence of LipA alone. The assays were performed in technical triplicates, the mean values and SD are shown.

D: LipA aggregation in presence and absence of LipH (LipA:LipH) or Skp (LipA:Skp) visualized via negative-stain TEM. Scale bars are indicated. 

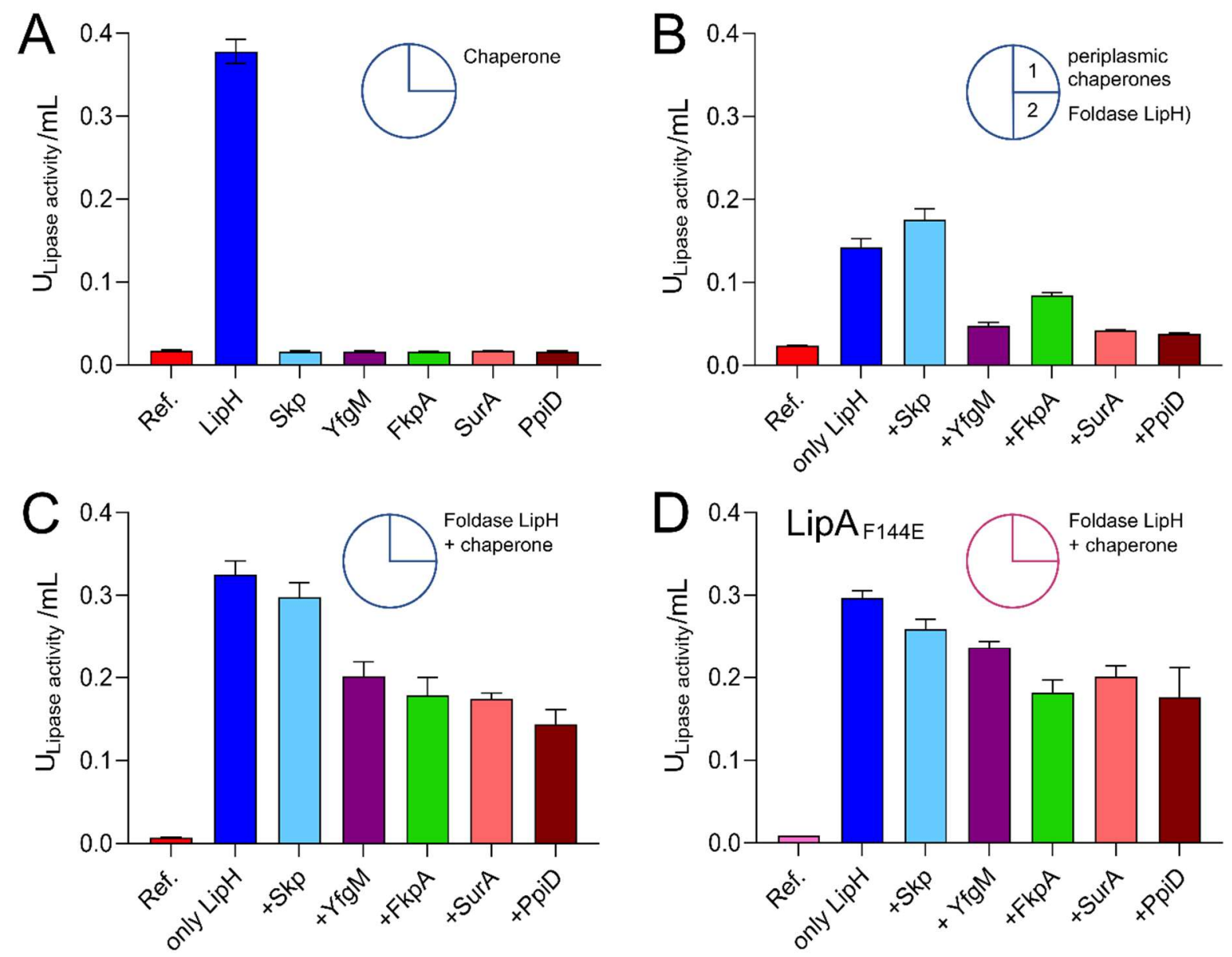

Figure 5. Interplay of periplasmic chaperones upon lipase activation. The lipase activity against $p$ NPB over the first 15 min of the hydrolysis reaction is shown in bars. Circle scheme describes the incubation steps. LipA activity in absence of chaperones is indicated as "Ref.".

A) Incubation of the wild-type LipA with either the foldase LipH or general periplasmic chaperones.

B) Initial incubation of the wild-type LipA with general periplasmic chaperones (1) followed by incubation with $\mathrm{LipH}(2)$.

C) Simultaneous incubation of the wild-type LipA with LipH and periplasmic chaperones.

D) Simultaneous incubation of the mutant $\mathrm{LipA}_{\mathrm{F} 144 \mathrm{E}}$ with $\mathrm{LipH}$ and periplasmic chaperones. The assays were performed in technical triplicates, the mean values and SD are shown. 

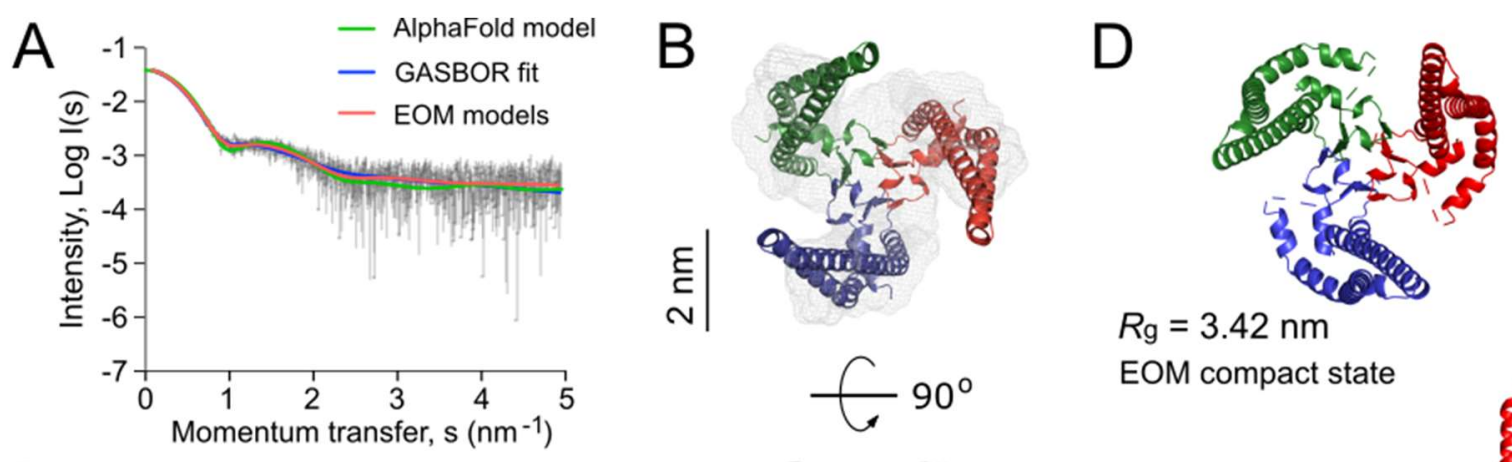

$R \mathrm{~g}=3.42 \mathrm{~nm}$
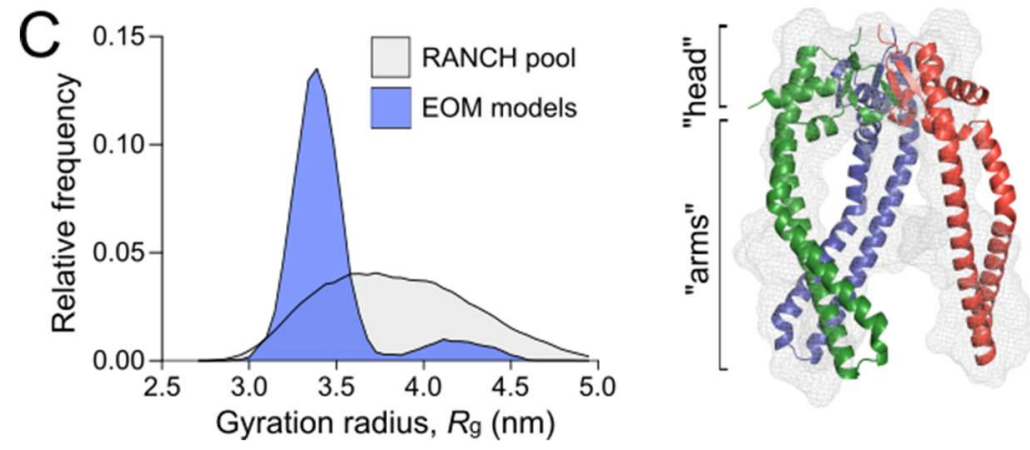

EOM compact state

Figure 6. $P$. aeruginosa Skp forms a flexible trimer in solution.

A) Experimental SAXS data curve is shown in grey dots with error bars. The intensity $(\log I)$ is displayed as a function of the momentum transfer (s). The intensity patterns of $\mathrm{Skp}_{3}$ models derived from GASBOR (blue), AlphaFold (green), and EOM (red) algorithms are overlaid.

B) The experimental SAXS envelope of $P$. aeruginosa Skp (grey mesh) calculated using GASBOR algorithm reflects the trimeric structure of the chaperone. The structural model of $\mathrm{Skp}_{3}$ is superimposed with the SAXS envelope, with each protomer coloured individually (red, green, blue). The "head" and "arm" structural domains of Skp are indicated. The scale bar is shown on side.

C) The distribution of $\mathrm{Skp}_{3}$ conformations differing by their gyration radii $\left(R_{\mathrm{g}}\right)$ calculated by EOM (blue). The original RANCH pool based on 10000 random models is shown in grey.

D) Representative conformations of $P$. aeruginosa $\mathrm{Skp}_{3}$ calculated by EOM in the compact $\left(R_{\mathrm{g}}\right.$ of $3.42 \mathrm{~nm}, D_{\max }$ of $9.73 \mathrm{~nm}$; fraction $\left.\sim 0.62\right)$ and the open $\left(R_{\mathrm{g}}\right.$ of $4.14 \mathrm{~nm}, D_{\max }$ of $13.63 \mathrm{~nm}$; fraction $\sim 0.12$ ) states. 

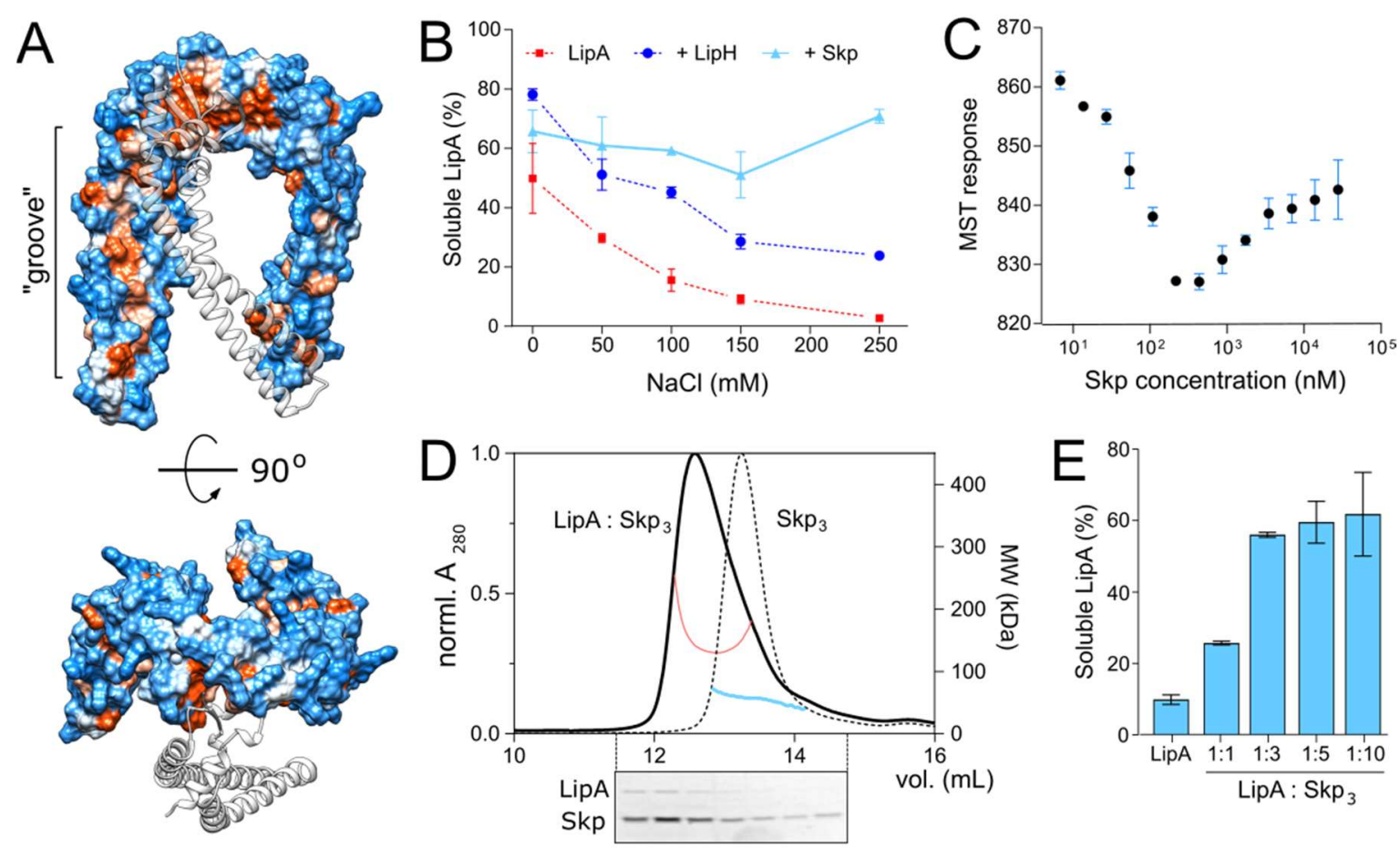

\section{Figure 7. Characterisation of LipA:Skp 3 interactions.}

A) Surface hydrophobicity plot of $P$. aeruginosa $\mathrm{Skp}_{3}$. The hydrophobic groove along the "arm" domain is indicated. Polar/charged residues are shown in blue, apolar in orange. One subunit within the Skp trimer is shown as a transparent ribbon for clarity.

B) Skp supports the solubility of LipA over a broad range of ionic strength. The soluble fraction of the wild-type LipA in presence of Skp (light blue) was determined from SDS-PAGE after the sedimentation assay at various salt concentrations. The assays were performed in technical triplicates, the mean values and SD are shown. Salt-dependent aggregation of LipA alone and LipA in presence of LipH are indicated in red and dark blue, respectively, and correspond to those in Figure 2B.

C) Microscale thermophoresis of LipA ${ }_{\mathrm{F} 144 \mathrm{E}}:$ Skp interaction, using fluorescently labelled LipA $_{F 144 E}$ and Skp titrations (monomers concentration indicated). The assay was performed in technical triplicates, the mean values and SD are shown.

D) SEC-MALS of the LipA $\mathrm{F}_{144 \mathrm{E}}: \mathrm{Skp}_{3}$ complex and $\mathrm{Skp}_{3}$ alone. Normalized UV absorbance of $\mathrm{LipA}_{\text {F144E: }}: \mathrm{Skp}_{3}$ (solid black line) and $\mathrm{Skp}_{3}$ (dotted black line), and the corresponding molecular weights are indicated. Below: SDS-PAGE of the LipA $\mathrm{F}_{\mathrm{F} 14 \mathrm{E}}: \mathrm{Skp}_{3}$ eluate.

E) Solubility of the lipase is dependent of the LipA:Skp 3 ratio. The soluble fraction of the wildtype LipA was determined from SDS-PAGE after the sedimentation assay at various $\mathrm{LipA}: \mathrm{Skp}_{3}$ ratios. The assays were performed in technical triplicates, the mean values and SD are shown. 